\title{
Impact of operational model nesting approaches and inherent errors for coastal simulations.
}

\author{
Jennifer M. Brown ${ }^{1 *}$, Danielle L. Norman ${ }^{1}$, Laurent O. Amoudry ${ }^{1}$, Alejandro J. Souza ${ }^{1}$ \\ ${ }^{1}$ National Oceanography Centre, Joseph Proudman Building, 6 Brownlow Street, Liverpool, \\ L3 5DA, UK \\ *Corresponding author Phone: +44 (0) 151795 4971, Fax: +44 (0) 151795 4801, Email: \\ jebro@noc.ac.uk (J.M. Brown) \\ Submission for Ocean Modelling special issue on "Coastal Ocean Modelling"
}

\begin{abstract}
A region of freshwater influence (ROFI) under hypertidal conditions is used to demonstrate inherent problems for nested operational modelling systems. Such problems can impact the accurate simulation of freshwater export within shelf seas, so must be considered in coastal ocean modelling studies. In Liverpool Bay (our UK study site), freshwater inflow from 3 large estuaries forms a coastal front that moves in response to tides and winds. The cyclic occurrence of stratification and remixing is important for the biogeochemical cycles, as nutrient and pollutant loaded freshwater is introduced into the coastal system. Validation methods, using coastal observations from fixed moorings and cruise transects, are used to assess the simulation of the ROFI, through improved spatial structure and temporal variability of the front, as guidance for best practise model setup. A structured modelling system using a $180 \mathrm{~m}$ grid nested within a $1.8 \mathrm{~km}$ grid demonstrates how compensation for error at the coarser resolution can have an adverse impact on the nested, high resolution application. Using 2008, a year of typical calm and stormy periods with variable river
\end{abstract}


influence, the sensitivities of the ROFI dynamics to initial and boundary conditions are investigated. It is shown that accurate representation of the initial water column structure is important at the regional scale and that the boundary conditions are most important at the coastal scale. Although increased grid resolution captures the frontal structure, the accuracy in frontal position is determined by the offshore boundary conditions and therefore the accuracy of the coarser regional model.

Keywords: ROFI; POLCOMS-GOTM; Liverpool Bay; model nesting; freshwater export; Initial and boundary conditions.

\section{Introduction}

A region of freshwater influence (ROFI) occurs where a river plume enters a shallow sea and the resulting stratification becomes influenced by the action of vertical mixing due to tides and winds (Simpson et al., 1993). A ROFI is one example of where exchanges between land and sea occur. Being able to represent ROFI dynamics accurately across temporal and spatial scales is therefore important for coastal management in relation to the transfer and fate of particles and nutrients in coastal seas. It is in this region that tidal and seasonal cycles influence sediment transport (e.g., Brown et al., 2015), pulses in primary productivity (e.g., Panton et al., 2012), and the trajectories of pollutants (e.g., Periáñez, 2005). To improve the understanding of physical processes within ROFIs, large scale observational campaigns (e.g. in the Rhine, de Boer et al., 2009) and modelling studies (e.g. in the Rhône, Reffray et al., 2004) are often employed. In this study observations (Howarth and Palmer, 2011) are used in combination with coastal models (Brown et al., 2015, O'Neill et al., 2012) to identify the main controls influencing the accuracy of an operational shelf sea model when applied in high resolution to a large dynamic ROFI. 
The Liverpool Bay ROFI, which is used as our case study, is situated in the northwest UK (Fig. 1). The large tidal range (in excess of $10 \mathrm{~m}$ on spring tides) generates fast tidal currents $(>1 \mathrm{~m} / \mathrm{s}$ ) that interact with the freshwater inflow complicating the dynamics of the region (Simpson et al., 1990). Stratification is promoted through surface heating and buoyancy input from river discharge and rainfall, while mixing is induced by tidal and wind stirring (Simpson and Bowers, 1981). The time-variation in the vertical stratification and remixing is important as it modifies the residual circulation that would occur under the barotropic conditions alone (Polton et al., 2013). The resulting residual circulation is a consequence of nonlinear tidal advection, lateral gradients in both density and sea surface elevation, frictional forces, the Coriolis effect and mixing processes (Fischer, 1976; MacCready and Geyer, 2010). Simulating these dynamics is not only important for water quality management, as in Liverpool Bay, but also, for example, where offshore industries are interested in the real-time ocean state (e.g., fishermen in Funka Bay, Japan (Nakada et al., 2012)).

Within Liverpool Bay the tidal ellipses are predominantly aligned east-west, with $50 \%$ of the amplitude accounted for by two dominant tidal components, the M2 and S2 constituents (Polton et al., 2011). The coastal front that forms within the bay moves between 5 and $10 \mathrm{~km}$ in response to semi-diurnal tidal straining and up to $35 \mathrm{~km}$ due to the spring-neap cycle. The fortnightly cycle in the frontal excursion of this particular front is much greater than other fronts across the northwest European Shelf (Hopkins and Polton, 2012). Stratification and remixing occurs over a large region $(\sim 30 \mathrm{~km}$ offshore $\times 20 \mathrm{~km}$ alongshore, Hopkins and Polton, 2012) making it important for the biogeochemical cycles and sediment transport, as it carries contaminants, nutrients and suspended particulate matter (Greenwood et al., 2011; Souza et al., 2013; Panton et al., 2011; Yamashita, et al., 2010). This site is therefore ideal to 
test model capability at simulating large scale spatial and temporal variability in frontal dynamics.

Tidal flow asymmetry, due to the shoaling depths causing the flood flow to be on average a factor of 1.2 faster than the ebb flow, leads to asymmetric tidal mixing (Polton et al., 2011) in addition to the typical strain induced periodic stratification (SIPS) (Simpson et al., 1990). During the ebb tide, the vertical shear in the current profile advects the surface freshwater layer further offshore from the coast. Low water stratification creates a baroclinic circulation with a northerly surface flow of $\sim 4.0 \mathrm{~cm} / \mathrm{s}$ and southerly near bed flow of $\sim 2.4 \mathrm{~cm} / \mathrm{s}$. On the flood tide stratification is broken down creating a well-mixed water column at high water (Palmer and Polton, 2011). This baroclinic flow, although weak in comparison to the tides, is approximately 4 times faster than the maximum (coastal) residual tidal current, making it a major contributor to the residual sediment transport pathways within this system (Brown et al., 2015).

Over an annual cycle Liverpool Bay shows no seasonal cycle in estuarine and river influence, receiving a mean freshwater discharge of $233 \mathrm{~m}^{3} / \mathrm{s}$ (Polton et al., 2011). Peak flows can however, be an order of magnitude larger (Palmer and Polton, 2011). Although the freshwater buoyancy input continually exceeds that of the seasonal solar heating (Palmer and Polton, 2011), there is evidence for seasonality in the occurrence of enduring stratification, with a greater likelihood in the summer months (Polton et al., 2011). There is also a seasonal cycle in storminess with higher waves between October to March (Wolf et al., 2011). The winds associated with storms are typically from southwest to northwest (Wolf et al., 2011), straining the front towards the English coast while locally generated waves act to increase mixing. 
Due to the coastal geography of Liverpool Bay, the large freshwater plume naturally moves north along the English coastline (Howarth et al., 2014) due to the Coriolis effect in the Northern Hemisphere (Garvine, 1987). Wind influence acting on the ROFI can strain the vertical density gradient (Scully et al., 2005), either enhancing (offshore winds) or reducing or even reversing stratification (onshore winds). In addition, under stratified conditions, upwelling winds typically spread the plume offshore, while downwelling winds compress the plume towards the coast (Whitney and Garvine, 2005). In Liverpool Bay winds that allow the plume to spread into the bay are associated with a northerly direction and occur for only $14 \%$ of the year (Howarth et al., 2014). A wind with a southerly component restricts the movement of the front offshore, while a wind directly from the east promotes the northerly along-coast transport.

Previous modelling studies (at 1.8 km, Polton et al., 2011; Palmer and Polton, 2011) have investigated the long-term time-average of the spatially varying horizontal density gradient. Here we extend this research with a higher horizontal resolution model to identify problems using a nested model setup for large dynamic ROFIs. A high $(\sim 180 \mathrm{~m})$ resolution model, designed to be part of a preoperational system combining real-time observation and model forecasts (Howarth et al., 2010), is applied to assess its capability at simulating the timevariation of the ROFI while constrained by the setup of the preoperational system. This high resolution nested model is designed to cover the region of high resolution observations with improved horizontal representation of the estuarine and channel-bank systems. Since observations are often limited to point locations for continuous (time series) monitoring and to short cruise periods over a regional area, this preoperational modelling suite has been designed to extend the real-time monitoring in time and space. A detailed model nest is required to understand the processes influencing the mixing of the freshwater plume under 
episodic river flow events (Polton et al., 2011). The Liverpool Bay model is therefore setup to cover the ROFI, which includes two strategic UK coastal management zones (Cooper and Pontee, 2006). Both the $1.8 \mathrm{~km}$ and $180 \mathrm{~m}$ models have been proven to accurately simulate: sea surface elevation at tide gauge locations (Brown and Wolf, 2009; Brown 2010) and Acoustic Doppler Current Profiler (ADCP) locations (Brown et al., 2011); velocity components at ADCP sites (Brown et al., 2013; Amoudry et al., 2014; Brown et al., 2015); and the frontal position compared with sea surface temperature (SST) from satellite imagery (Bricheno et al., 2014; Hopkins and Polton, 2012), focusing particularly on the $17^{\text {th }}$ February 2008 (Bricheno et al., 2014). In the case of the $1.8 \mathrm{~km}$ model further validation of temperature and salinity fields has been carried against Ferry Box observations (O’Neill et al., 2012) and Conductivity, Temperature and Depth (CTD) observations (O’Neill et al., 2012; Polton et al., 2013). Studies have also used HF radar to validate the surface currents across the bay (Polton et al., 2013). The aim of this research is to investigate the sensitivity of a high resolution model nest to both boundary forcing and initial temperature and salinity fields, when constrained to a 3 grid modelling system by operational requirements to be efficient. These findings will inform the wider coastal ocean modelling community of the potential sources of inherent error due to model nesting, when simulating the dynamics of a large ROFI with an extensive frontal excursion. Although this system represents a typical ROFI, with large estuary systems creating strong horizontal gradients from multiple low freshwater inflows under the influence of wind and tidal straining, it also contains the complexities and combinations expected in many shelf seas, such as a large tidal range, strong density gradients and complex bathymetry. Identifying inherent problems for localised operational nested model applications in this location is therefore applicable to many other coastal modelling studies. 
We describe the modelling and observational methods in Section 2, with a detailed description of the observed events during the study period. A comparison of the annual simulation with available data is presented in Section 3 and the resulting model sensitivity to the treatment of open boundaries and initial conditions is discussed in Section 4. In Section 5 it is concluded that the compensation for numerical diffusion within the coarse regional model can have adverse effects within the local nested model and that the most important control on the model accuracy is the boundary conditions at the high $(180 \mathrm{~m})$ resolution and initial conditions at the coarser resolution $(1.8 \mathrm{~km})$.

\section{Modelling approach}

We assess the capability of the Proudman Oceanographic Laboratory Coastal Ocean Modelling System (POLCOMS), which has been previously found to accurately simulate frontal position across the northwest European shelf (Holt and Umlauf, 2008), to simulate the frontal displacement within the highly dynamic large ROFI of Liverpool Bay. To assess the model's capability in coastal waters it is compared with observations (Fig. 1) for the year 2008, which has typical, but varied, combinations of river inflow with calm and stormy conditions when compared with long-term observations (Norman et al., 2014b). Error metrics are applied to validate the model setups with available observations to assess the capability in simulating the spatio-temporal variation in the density gradients within Liverpool Bay.

POLCOMS is formulated in spherical polar sigma coordinates solving the full UNESCO equation of state and the incompressible, hydrostatic, Boussinesq equations of motion (Holt and James, 2001). Turbulent terms in the governing equations are computed via the coupling of POLCOMS to the General Ocean Turbulence model (GOTM, Umlauf et al., 2005), where the $\mathrm{k}-\varepsilon$ closure scheme is implemented with stability functions derived from the second-order 
model of Canuto et al. (2001). This coupling exchanges information each computational time step and allows more options to be considered within the turbulence scheme (Holt and Umlauf, 2008), such as TKE injection at the surface to represent white-capping waves. Advective terms in POLCOMS are computed using the piecewise parabolic method (PPM, Colella and Woodward, 1984), which has low numerical diffusion and better preserves frontal features (James, 1996; 1997). By default POLCOMS does not apply explicit horizontal diffusion and at the Liverpool Bay scale consideration of diffusion has little impact on the frontal position (Norman et al., 2014d).

\subsection{Model setup}

The Liverpool Bay (LB) model (Fig. 1) extends from $4.00^{\circ} \mathrm{W}$ to $2.56{ }^{\circ} \mathrm{W}$ and $53.14{ }^{\circ} \mathrm{N}$ to $53.92{ }^{\circ} \mathrm{N}$. It has a horizontal resolution of $180 \mathrm{~m}$ and 20 vertical sigma levels within the water column, which are terrain following, and accounts for wetting and drying of the intertidal zone within Liverpool Bay. The model is setup using the baroclinic structured B-grid model POLCOMS (Holt and James, 2001) and is nested in one way into a regional Irish Sea (IRS) domain, which extends from $7.00{ }^{\circ} \mathrm{W}$ to $2.7^{\circ} \mathrm{W}$ and $51.00{ }^{\circ} \mathrm{N}$ to $56.00{ }^{\circ} \mathrm{N}$ (Fig. 1). This model has a $1.8 \mathrm{~km}$ resolution and 32 vertical levels within the water column and a minimum depth of $5 \mathrm{~m}$ locally in Liverpool Bay and $10 \mathrm{~m}$ elsewhere. Due to the shallower depths within the LB domain (<50 m, Fig. 1) a lower number of sigma levels still maintains a high vertical resolution, but prevents the layer thickness becoming less than the bed roughness length scale $(2.5 \mathrm{~mm})$ in regions that wet and dry. In turn, this avoids instability occurring in the computation of bed shear stresses when considering sediment transport. The minimum depth considered as wet within the wetting and drying algorithm is $5 \mathrm{~cm}$ within this model setup, below this threshold the grid cells are considered as dry and temporarily removed from the computation. 
Typically a resolution of $200 \mathrm{~m}$ (Duran-Matute et al., 2014) to $500 \mathrm{~m}$ (de Boer et al., 2006) is required to accurately model a ROFI. Although the ratio between nested grid resolution is typically 3 to 5 (Warner et al., 2010) a factor of 10 is used for this ROFI application to go straight to the highest resolution of $180 \mathrm{~m}$ from $1.8 \mathrm{~km}$. This ensures the LB model resolution is comparable with the Rossby Radius in Liverpool Bay ( $100-200$ m, Bricheno et al., 2014), enabling it to be eddy permitting (Holt and Procter, 2008). Inclusion of an intermediate grid to bridge between the $1.8 \mathrm{~km}$ and $180 \mathrm{~m}$ models over the eastern Irish Sea is not included as the number of model nests is limited to 3 replicating the preoperational system designed for Liverpool Bay (Howarth et al., 2010). An additional nest would become inefficient for operational forecasting. Typically operational systems consider 2 model grids (e.g. Warner et al., 2010; Sánchez-Arcilla, et al., 2014) with the highest resolution in the order of $1-2 \mathrm{~km}$. The preoperational POLCOMS system for the Irish Sea similarly applies a 2 nest system, with a $12 \mathrm{~km}$ Atlantic Margin model (AMM), extending from $11.92{ }^{\circ} \mathrm{W}$ to $12.92{ }^{\circ} \mathrm{E}$ and $48.06{ }^{\circ} \mathrm{N}$ to $62.95^{\circ} \mathrm{N}$, and a one-way nested $1.8 \mathrm{~km}$ Irish Sea model (O’Neill et al., 2012). While the $1.8 \mathrm{~km}$ resolution model is adequate in the western Irish Sea, where the Rossby Radius varies between $\sim 1-2 \mathrm{~km}$ (Holt and Procter, 2003), it is too coarse to be eddy permitting in the eastern Irish Sea (Bricheno et al., 2014). However, validation has shown it is still capable of simulating the frontal position, although the small scale variability is lost requiring the need for an additional high resolution nest in Liverpool Bay (Bricheno et al., 2014). Numerous studies validating the third $180 \mathrm{~m}$ nested model against observations (e.g., Bolaños et al., 2013; Brown et al., 2013; Amoudry et al., 2014; Bricheno et al., 2014; Ramirez-Mendoza et al., 2014; Brown et al., 2015) gives confidence in this $1.8 \mathrm{~km}$ to $180 \mathrm{~m}$ nested configuration. 
Here a sensitivity analysis of the IRS to LB model nesting is performed to assess the influence of initial conditions and boundary conditions on the LB ROFI simulation. This assesses inherent errors that can occur within a preoperational suite that downscales to a high $(180 \mathrm{~m})$ resolution. Here the IRS and LB models are nested to match the preoperational approach. An exchange of information from the IRS to the LB model comprises surface elevation and depth-varying velocity components, which in this case were provided at an hourly interval, and daily mean depth-varying fluxes of temperature and salinity. The IRS model receives the same boundary forcing parameters at the same frequency from the preoperational AMM. The western boundary of the LB model is positioned just beyond the $99 \%$ confidence contour of the frontal position for summer neap tide conditions $\left(3.9^{\circ} \mathrm{W}\right.$, Hopkins and Polton, 2012). These conditions determine the most offshore location of the front identified from 5 years of SST satellite imagery. During spring tides in all seasons and neap tides in winter the front remains to the east of $3.9^{\circ} \mathrm{W}$. It is only with the addition of summer heating at neap tide that the front can extend to $4.25^{\circ} \mathrm{W}$ (with $1 \%$ confidence). Using the preoperational IRS model in combination with the satellite imagery confirms the validity of the modelled SST, which in turn indicates a more limited offshore extension of the freshwater signature relative to the SST (Hopkins and Polton, 2012) suggesting the ROFI extends to a maximum of $4{ }^{\circ} \mathrm{W}$ (Polton et al., 2011). The model also reveals that the extreme offshore frontal movement beyond $4{ }^{\circ} \mathrm{W}$ observed in SST imagery is limited to a thin surface plume. Weak horizontal gradients remain across the majority of the water column. The boundary of the LB model is therefore positioned at $4^{\circ} \mathrm{W}$, the offshore limit of the ROFI, where weak horizontal gradients only exist at times of low (neap) tidal straining. Daily-mean temperature and salinity conditions as specified in this model configuration can therefore be applied consistently between each model nest to maintain a consistent preoperational model setup. 
The initial temperature and salinity conditions are imposed from the preoperational modelling suite (O'Neill et al., 2012). The long-term daily simulation of this suite at the National Oceanography Centre as part of the Liverpool Bay Coastal Observatory (Howarth and Palmer, 2011) enables the initialisation of the models. Since the offshore boundary forcing and initial water column structure are in equilibrium, only a 1 month spin-up period (approximately the time for $50 \%$ of a riverine tracer to be lost from Liverpool Bay, Phelps et al., 2013) is required to allow slight adjustment to the higher frequency atmospheric forcing and observed river flows in this model application. Two sets of initial conditions for the IRS model, run as part of this analysis, are created. The first set is consistent with the AMM model providing the boundary forcing, while the second set has higher resolution and is directly imposed from the preoperational IRS model (see Table 1). For the Liverpool Bay model the preoperational IRS model provides the initial conditions (see Table 2).

River discharge is incorporated into this modelling application as a daily mean flow rate for all rivers with a 2008 record. Due to the position of the river gauges outside the model domains a downstream catchment factor for the location of the river gauge relative to the mouth is applied (see Marsh and Sanderson, 2003). In the IRS model the salinity is set to 20 psu to represent brackish water since the estuary region is not resolved to the river source location. A sensitivity analysis was conducted to calibrate this value using observations in Liverpool Bay (see Norman et al., 2014a). The better coastal resolution of the LB model allows the river water to enter as an up-estuary freshwater ( 0 psu) source. Air temperature inland of the river gauge is used as a proxy for seasonality in river temperature in the absence of observations. Sensitivity analyses for both the IRS (see Norman et al., 2014a) and LB (see Norman et al., 2014d) models find that river temperature has a low impact on the nearshore 
density variability. A $5{ }^{\circ} \mathrm{C}$ change in temperature is required to have the same change in density as a 1 psu change in salinity. Since salinity is the main driver in Liverpool Bay ROFI (Polton et al., 2011) and atmospheric temperatures are not that dissimilar to the coastal surface water temperature, river temperature has low impact on the simulations in comparison to the seasonal surface heat flux. In the preoperational model setup used to provide initial conditions, the daily-mean flow rate of the representative river climatology (Young and Holt, 2007) is used with a salinity imposed as 0 psu and no inclusion of river temperature.

The preoperational POLCOMS calculates momentum and surface heat fluxes using bulk formulae following the COARE v3 algorithm (Fairall et al., 2003). For the momentum fluxes in this (IRS and LB) application the wind stress is instead calculated using the Charnock (1955) formulation with a Charnock constant of 0.0185 to improve the circulation within Liverpool Bay (Brown et al., 2013). The models nested here use the same atmospheric forcing from the UK Meteorological office numerical weather predictions, which comprises a European shelf model nested within a global model. The nested horizontal resolution is $0.11^{\circ}$ $\times 0.11^{\circ}$ (approximately $12 \mathrm{~km}$ ) for hourly wind and air pressure fields and 3 hourly air temperature, specific humidity and cloud cover fields. The same $3 \mathrm{~h}$ data are used in the preoperational IRS model along with $3 \mathrm{~h}$ air pressure and wind. For the larger preoperational AMM domain $6 \mathrm{~h}$ global atmospheric data at a $0.83^{\circ} \times 0.56^{\circ}$ horizontal resolution with the inclusion of precipitation is used.

The setup used in this application has previously been found to be accurate when modelling shelf seas (e.g. Holt and Umlauf, 2008), but the question of whether it is adequate for more 
local coastal modelling remains. To test this we assess the ability of the IRS model and the LB model to simulate the Liverpool Bay ROFI dynamics.

\subsection{Observations}

To assess the time variation in coastal water properties (temperature and salinity), available time-series data at Sites A and B are used. These moorings were situated in mean depths of $23.5 \mathrm{~m}$ (Site A at $53^{\circ} 32^{\prime} \mathrm{N} 3^{\circ} 21.8^{\prime} \mathrm{W}$ ) and $25.0 \mathrm{~m}\left(\right.$ Site B at $\left.53^{\circ} 27^{\prime} \mathrm{N} 3^{\circ} 38.6^{\prime} \mathrm{W}\right)$. The coastal site (A) was positioned close to the entrance of the main channel in the outer Mersey estuary, where the river flow enters Liverpool Bay. The nearshore site (B) was positioned $21 \mathrm{~km}$ to the west with the intention to monitor horizontal gradients across a transect of Liverpool Bay. However, the positioning of this secondary site was influenced by other coastal freshwater inflows and was relocated in 2010 (Howarth and Palmer, 2011). For this application only the temperature and salinity records are used (e.g., Fig. 2 e and f). The data are obtained at 3 levels: $5 \mathrm{~m}$ below the surface (mbs), $10 \mathrm{~m}$ below the surface and $0.5 \mathrm{~m}$ above the bed (mab). Initial analysis of the density difference between the observed levels (stratification) and the metocean parameters (driving forces) finds no clear correlation between the variability in the time series (see Norman et al., 2014c and Fig. 2). Flow rate from the river Dee, which typically exits the estuary from the eastern channel, had the highest correlation with density differences at Site A and the tidal cycle (elevation) had highest correlation with the density differences at Site B. This suggests stratification is controlled by different dominant processes across the bay, with stratification at Site A being mostly influenced by river flow, while at Site B it is mostly tidally influenced.

To assess model capability, observations collected as part of the Liverpool Bay Coastal Observatory (Howarth and Palmer, 2011) are combined with other available monitoring 
networks (Fig. 2). The data used include river discharge from gauges on the closest river systems (the Mersey and the Dee, Fig. 2a), wind speed (Fig. 2b) and direction (Fig. 2c) from a weather station mounted on an island in the mouth of the Dee Estuary, tidal conditions from the Liverpool Gladstone Dock tide gauge (Fig. 2d), and coastal water properties (e.g., salinity, Fig. 2 e and f) at two fixed moorings (Sites A and B, Fig. 1). The observations show the bay experiences low river flow during the summer months (day $125-225$, Fig. 2a) and variable wind conditions, with extremes ( $>90^{\text {th }}$ percentile value) occurring throughout the year (Fig. 2b). The wind direction is variable, but during the first 60 days a strong southeast to southwest component persists (Fig. 2c). The large tidal range $(<10 \mathrm{~m}$, Fig. $2 \mathrm{~d})$ causes semidiurnal straining of the salinity values (Fig. 2 e \& f). There is no clear spring-neap cycle, although this does become more evident when assessing the vertical salinity difference or stratification (Norman et al., 2014c). The running mean in salinity indicates the longer term variability in the frontal position, decreasing as the front moves offshore. Stratification is more frequently observed nearer to shore (indicated by the difference in the running mean of the salinity at $5 \mathrm{mbs}$ and $10 \mathrm{mbs}$, Fig. 2e compared with Fig. 2f). It should be noted the pycnocline could be lower than the observed level, so periods of stratification are only suggestive. During the initial winter months salinities are high until upwelling winds enable freshening across the bay (day 81) with the release of the coastally trapped river water. The salinities gradually become restored to higher values during the months of low river flow. Over the year short-term reduced salinity events occur when high river flow coincides with northwest to northerly winds.

Select events (Fig. 2) for the year 2008 show the complexity of the Liverpool Bay ROFI. The vertical line represents a change in model response within the results presented (Section 3) and is used in the discussion (Section 4) of appropriate boundary conditions. In Liverpool 
Bay there is no single process that clearly dominants the offshore export of freshwater towards the fixed moorings (Fig. 2). The horizontal gradients in salinity and the frontal position are influenced by river discharge, which adds freshwater to the system, and by wind influence, which enhances or prevents the export of brackish coastal waters offshore. By identifying river events over the annual period the contrasting coastal response can be seen. For example (Fig. 2), on day 21 there is a high river discharge ensued by a wind backing towards southeast. This turning wind direction (through south) limits freshwater export from the estuarine systems and compresses the front towards the coast. The salinity at Site A dips for only a short time during the ebb tide and rebounds on the flood. After the initial period of high river discharge ( $<$ day 42, Fig. 2a), the salinity at Site A is reduced over a number of days during a period of neap tides and low south-easterly winds ( day $42-50$, Fig. 2 b to d). These conditions enable the transport of the trapped freshwater from the estuaries, particularly the Dee, northward along the coast. Site B does not show this reduction in salinity due to its greater distance from the English coast. Low river flow, a veering wind to the southwest and increasing tidal range (after day 48, Fig. 2 a, c, and d) allows mixing and rebound of the salinities over similar time scales. As the salinity at Site A rebounds the salinity at Site B shows increased semidiurnal variability as the spring tides mix the freshwater further offshore widening the area influenced by horizontal density gradients. The next rapid drop in salinity at Site A ( day $81-82$, Fig. 2e, marked by the vertical line) is caused by a northerly wind followed by relatively long consistent period of north-westerly (upwelling) winds, enabling the front to move offshore reducing the salinity at both mooring sites. The difference in salinity at Site B suggests that following this event the conditions enable the water column to more easily stratify further offshore during low water $(\sim$ day $82-$ 86, Fig. 2e) due to the westward movement of the front. This event shows less stratification than other export events at Site A and does not coincide with high river discharge; it follows 
a period of prolonged high freshwater inflow into the system that has potentially been coastally trapped by the prevailing winds. Unlike other export events, the response of the upper salinity limit is slow to rebound from this low salinity state, with the salinities at the moorings increasing until approximately day 184 at Site A and day 200 at Site B. The earlier re-freshening of Site A coincides with the increase in freshwater discharge, spring tides and south-easterly winds promoting the export of freshwater north along the English coast, thus influencing Site A but not B. On day 200 a westerly wind inhibiting the northerly freshwater transport, promoting the front to move offshore, coincides with spring tide mixing, causing the salinity to drop at both sites. This upwelling event is timely as the atmospheric heat transfer will also be acting to reduce the density of the shallow coastal waters ( day $125-$ 250, see Norman et al., 2014d) enabling the freshwater to propagate further offshore under the weakened density gradient, hence enforcing a slow rebound. Later events, after day 250, are again associated with high river flows and/or north-easterly winds. For example, around day 250 there is high river discharge coincidental with northerly wind, which promotes the export of freshwater offshore towards Site A, causing a period of reduced salinity. All but the export event on day 81-82 rapidly recover. Observations at Site B (Fig. 2f) show much less response to export events and a weaker semidiurnal straining signal, suggesting the front (or ROFI) rarely propagates this far offshore. However, a delayed response to the freshwater export on day 81 is evident, thus it marks a change in the ROFI extent and offshore conditions, which is important for modelling studies to capture.

To make a better assessment of the east-west horizontal gradients across the bay CTD measurements are used from three cruise periods during 2008. CTD cast data across the grid (Fig.1) are analysed during the contrasting conditions of: 10 -11 January 2008, which experienced the highest river flows seen during 2008 accompanied by stormy conditions, 13 - 
16 May 2008, when conditions were calm with low river outflow, and 30 - 31 July 2008, with calm weather and moderate river flow. Both the January and July cruise occurred around spring tides, while the May cruise occurred closer to neap tide. The full CTD grid has been used to assess model performance by Norman et al. (2014d), but here we focus on the transect that lines up with the mouth of the Mersey estuary and Site A (at $53^{\circ} 32^{\prime} \mathrm{N}$ ) as it provides a good indication of the horizontal gradient between the estuary inflow and offshore, while also representing a transect between the fixed mooring Sites A and B (Fig. 1).

\subsection{Validation methods.}

To assess model performance and sensitivity to setup, error metrics are applied to the time varying temperature and salinity conditions at the fixed moorings and to the density anomaly across the chosen transect (see Fig. 1 for locations). For both observations and model output the density anomaly is calculated as a function of both temperature and salinity using the equation of state of seawater (EOS80, Fofonoff and Millard, 1983). To enable modelobservation comparisons the data have to be interpolated in both time and space. For comparison with the fixed mooring data, the numerical data are interpolated to the same depths as the observations. The 10 minute measurements are interpolated onto the 30 minute model output for ease of quantitative comparison and to remove any time drift that may have occurred during the instrument deployment. To validate the CTD transect the observed data are interpolated onto the modelled sigma levels. The model data are then extracted from the nearest grid point to the CTD cast location at the nearest (30 minute) time interval to the time of that cast, which is constrained my the boat track. The horizontal gradients presented across the transect in later figures $(10-12)$ are therefore not synoptic in time. In particular the points along the transect in May were not visited in sequential order. The observational grid limits the horizontal resolution to approximately 5 nautical miles $(\sim 9.3 \mathrm{~km})$, while the model 
sigma layers determine the vertical resolution. Since the CTD observations are not synoptic across the grid, an assessment of the horizontal and vertical gradients using this data set for a single cruise period is prevented. The density anomaly is therefore only used to determine the model's capability at representing spatio-temporal variability of the frontal structure and not to investigate the spatial variability of the water column structure.

At the mooring sites and across the CTD transect the following metrics are applied: the bias of the mean (Bias), the root mean squared error (RMSE) and the model skill $(D)$ following Willmott (1981). The Bias is defined as:

Bias $=\bar{M}-\bar{O}$

where $M$ represents the model values, $O$ the observed values and the overbar denotes the mean value of the time series. The Bias is therefore a measure of the models ability to simulate the mean value over the annual cycle. A value of 0 corresponds to an unbiased estimator; a positive value implies the model is over-predicting and a negative value implies the model is under-predicting. The RMSE is defined as:

$R M S E=\sqrt{(M-O)^{2}}$

where a smaller value indicates better model performance, and the model skill is defined as:

$D=1-\frac{\overline{(M-O)^{2}}}{(|M-\bar{O}|+|O-\bar{O}|)^{2}}$

$D$ takes values between 0 and 1 , where 0 implies no agreement and 1 implies total agreement.

\subsection{Model scenarios.}

Multiple simulations were performed in a sensitivity analysis of the numerical results to assess the best model setup for the chosen period. The simulations that had noticeable influence on model capability are detailed in Table 1 for the IRS model and Table 2 for the LB model. Additional simulations considered in the LB model assessed the sensitivity to 
river source location, estuarine channel depth, a smoothed representation of the coastal bathymetry, and model parameter settings for the parameterisation of turbulence in both POLCOMS and GOTM. Both model applications were also analysed to assess their sensitivity to river inflow salinity and temperature. However, it was found that the factor with most impact was the offshore boundary conditions, which were in turn strongly dependent on the initial conditions imposed within the IRS model. The primary approach to the model nesting was a setup that imposed initial conditions that were consistent with the boundary conditions, i.e., the initial conditions were taken directly from the AMM providing the boundary conditions for the IRS model (IRS1, Table 1). Since model accuracy in coastal waters is reduced with lower grid resolution the density, salinity and temperature conditions at Sites A and B were used in a repeated simulation to bias the initial conditions to assess if the results could be optimised (e.g., IRS2, Table 1). The bias was implemented as an increase in salinity calculated to reflect the average difference, for the 3 depth levels at both sites, between the unbiased simulation and the observations at the time instance of the first observation. A final simulation (IRS3, Table 1) used higher resolution initial conditions, obtained at the same $1.8 \mathrm{~km}$ resolution from the preoperational IRS model (Fig. 3). The preoperational IRS model provided the initial conditions for the LB simulations, while the IRS simulations run here provided the boundary conditions (LB1, LB2 \& LB5, Table 2). Additional simulations (LB3 \& LB4, Table 2) were performed to bias the initial conditions of the LB2 simulation (nested within the unbiased IRS simulation), as applied in the IRS setup using the fixed mooring observations. The short (1 month) spin-up time is less than the flushing time for water in both the Irish Sea ( 1 year, Bowden, 1980; Dabrowski et al., 2012) and Liverpool Bay ( 136 days, Phelps et al., 2013). This allows all the applied biases to the initial conditions, to have an influence on the model results within the study period. 


\section{Results}

The results are presented for the simulations highlighted in Tables 1 and 2. To identify the different model setups the naming convention IRS (Irish Sea) and LB (Liverpool Bay) are used to identify the model domain being considered and the associated number indicates the setup as defined in Tables 1 and 2. The results are first presented for the IRS model at the coarser resolution and then for the nested high resolution LB model. In the high resolution LB model results, the offshore boundary conditions have stronger influence on the predicted water column structure than the coastal inflow. Here, a sensitivity analysis of the initial and boundary conditions is presented to identify an appropriate nesting approach to accurately model a large and highly dynamic ROFI with a structured grid system for operational purposes. The IRS results are shown to explain the consequent influence of the changes implemented at this resolution on the LB model when applied as boundary conditions.

Although temperature controls the annual variability in the density structure, the short-term (tidal to storm duration) variability is dominated by straining and mixing of the coastal salinity gradient. For 2008 the sea temperature ranges from approximately 5 to $20{ }^{\circ} \mathrm{C}$ and the salinity varies from 31 to 34 psu. The results presented focus on the salinity time series data 5 mbs at the fixed mooring sites. This indicates the time-variability in model performance, which is found to be similar at the $10 \mathrm{mbs}$ and $0.5 \mathrm{mab}$ depth levels. Only salinity is presented as it dominates the density structure in this region. The accuracy of the initial salinity structure (Fig. 3) and offshore values are found to greatly influence the model's capability at representing the horizontal density gradients across the ROFI. The density anomaly is presented for the CTD transect to capture the model performance in representing the water column structure at certain times of the year. The CTD transect are representations of the processes influencing the horizontal and vertical gradients in the water column at that 
time, so density is used to capture the influence of both temperature and salinity at that instance.

\subsection{Irish Sea model salinity time-series}

The models' capabilities at simulating the 25 -hour running mean of the annual salinity time series data are shown in Figure 4. A clear under-prediction in salinity at the two mooring sites is seen for the majority of the year when using the default IRS model setup (IRS1, Fig. 5). It is not until after day 275 that the modelled salinity time series becomes more aligned with the observations. A bias in the initial conditions (IRS2, Fig. 5) has an impact for the full duration of the study and is not limited to the initial few days or months. This is a consequence of the renewal time for water within the Irish Sea being of the order a year (Bowen, 1980; Dabrowski et al., 2012). At Site A the simulation is improved, although the salinity is now over predicted (Fig. 5a), whereas at Site B a larger over prediction in salinity, especially in later months, reduces the model accuracy (Fig. 4). This is due to the bias compressing the front towards the coast (see next Section 3.3). The bias in initial conditions also prevents the gradual movement of the front offshore ( day 60-81). At Site B this is seen as a shortduration sudden decrease in salinity during day 81 (Fig. 5b). Improving the resolution of the initial conditions (Fig. 3) has a slight impact (IRS3, Fig. 5). The largest change is an increase in the salinities at Site B ( day $20-70$, Fig. 5b) in response to the wind forcing (Fig. 5b). The more highly resolved initial conditions (IRS3) do not produce a consistent change in salinity across the region (Fig. 3). The stronger horizontal gradients, due to fresher coastal water and more saline offshore water due to the sharpening of the front towards the coast, change the water column structure, which influences the short-term straining of the water column (not shown). The salinity range during tidal straining is more frequently found to be slightly reduced at both sites. This typically occurs in response to the front being constrained 
closer to the coast. The increase in the lower salinity limit increases more than the increase in the upper limit, if the upper limit adjusts at all. In turn this causes a slight increase in the long-term mean salinity values (Fig. 5, particularly at Site B).

The validation of each model run is presented in Figure 4. On average, over the annual period, there is very little difference between the model performances. At Site A IRS2 tends to more frequently perform slightly better and at Site B IRS2 closely followed by IRS3 tends to give slightly improved performance. In the next section (3.2) the impact of the modifications to the IRS model on the accuracy of the LB model through the provision of the boundary conditions are assessed. This will identify if the offshore conditions or the internal dynamics within the ROFI are more influential on accurately simulating the water column structure and front formation. The bias in IRS2, and to a lesser extent in IRS3, is expected to noticeably increase the salinities in the LB model at the onset, but the annual response will depend on how important the offshore boundary conditions are on the internal dynamics compared with the river inflow and local mixing processes.

\subsection{Liverpool Bay model salinity time-series}

The salinity at 5 mbs is shown for both the model and observations during 2008 in Figure 6. The annual variability in salinity shows a clear difference in model performance prior to and after the upwelling event (day 81, Fig. 6). LB1 with biased boundary conditions from the IRS model performs the best during the initial months. LB2 with unbiased boundary conditions is then more accurate after the upwelling event. Adjusting the initial salinity conditions of the unbiased boundary condition simulation (Fig. 7) by the same amount as in the IRS model (1.15 psu) and then by the slightly greater difference between the LB2 (unbiased IRS BC) and average observed value at the moorings (1.89 psu), continually improved the simulation. 
However, the results (LB3 and LB4, Fig. 7) rapidly converge back to those of the unbiased initial condition (LB2, Fig. 7) due to the short flushing time of Liverpool Bay (Phelps et al., 2013). The timing of the upwelling event (day 81) affects the water exchange (Dabrowski et al., 2010) close to the start of the simulation, thus enabling the equilibrium state to be achieved rapidly after this event and within the flushing time of the bay ( day 105 when including the model spin-up period). This suggests that the accuracy of the LB model is controlled by the accuracy of the boundary conditions from the IRS model. Improving the IRS model's initial conditions (IRS3, Fig. 3) has a more noticeable longer-term impact on the nested LB model. The improvement is greater in the initial months before the upwelling event (LB5, Fig. 6), but the increase in salinity still remains less than that required to reach the values observed. When using these IRS3 model boundary conditions the salinity tends towards the higher observed values. It is therefore suggested that the accuracy of the initial water column structure in the coarser IRS model across the coastal sea is the most important factor influencing the accuracy of the local LB model. It is this structure that influences the IRS model's ability to respond more realistically to wind conditions. Tuning the IRS model to more accurately capture the observed ROFI conditions at the points of observation is found to cause an adverse impact on the accuracy of the high resolution LB model simulation. Improvement is actually needed to capture the offshore salinity structure that provides the locally nested model with boundary conditions. Without offshore observations at the boundary of the local model we find calibration of the coarse model can only be achieved by assessing the impact of modifications to the coarse IRS model on the accuracy of the high resolution LB model, which is computationally expensive.

As expected the LB model performs better than the IRS model due to its higher resolution (Fig. 4). The improved resolution through nesting prevents the need for the IRS model to be 
improved through a bias in initial salinity conditions. Accounting for inaccuracy in the ROFI dynamics within the IRS model is found to reduce the accuracy of the offshore and therefore the boundary conditions to the LB model. It is therefore suggested that model validation against observations within the ROFI should be performed only on the highest resolution grid within the nest, or that validation of coarser grids should be restricted offshore to where the nested model boundaries fall, if observation are available.

\subsection{Surface salinity maps of the ROFI extent}

The modelled surface salinity is plotted at low water during the maximum extent of the freshwater export following the winter period (day 81, Fig. 8). This demonstrates how the grid resolution is important to maintain the structure of the front. Although both models display a similar frontal position, the lesser resolved structure in the IRS model (Fig. 8 a and c), due to the lower $1.8 \mathrm{~km}$ horizontal grid resolution, reduces the model accuracy at the points of observation (Site A and B), which are positioned where complex spatial gradients occur within the ROFI. To compensate for the lack of structure and numerical diffusion of freshwater offshore (due to grid resolution), an increase in the offshore salinity (IRS2, Fig. 8c) is found to improve the representation of the ROFI (IRS2, Fig. 5) in the IRS model. In the LB model a much sharper frontal density gradient with more horizontal structure is produced (Fig. $8 \mathrm{~b}$ and d). An increase in the boundary condition salinity in the LB model clearly constrains the freshwater plume towards the coast (LB1, Fig. 8d).

\subsection{The CTD density anomaly transect}

The CTD data enables a more comprehensive picture of the water column structure to be assessed. The observed density anomaly is plotted for each cruise period for the model simulation IRS1, IRS2, LB1 and LB2 (Tables 1 and 2). The observational limitations prevent 
these results providing the instantaneous water column structure of the cross-section and thus, the figures presented do not provide a snapshot of density anomaly at a single given time. However, these results are still a useful tool to assess the model's spatio-temporal performance. The models' capabilities at simulating the density anomaly are shown in Figure 9.

In January (Fig. 10) there is a clear horizontal gradient across the observational transect, while the water column is typically well-mixed in the vertical. Both model setups reproduce the vertically uniform structure. However, errors occur in the actual density values and the horizontal gradient. The unbiased IRS model (IRS1, Fig. 10b) under predicts the density and the gradient over the transect due to over prediction of the freshwater export towards the west. When the initial conditions were biased the density values across the transect increase (IRS2, Fig. 10c), but a sharper than observed gradient occurs between $-3.6^{\circ}$ and $-3.65^{\circ}$ longitude and the offshore density is too high. The LB model (LB2, Fig. 10d) has a more accurate gradient, but the density is under predicted. Using the biased IRS boundary conditions improves the density values within the ROFI (LB1, Fig. 10e), but offshore the density gradient remains too weak as the density to the west is under predicted. This suggests that during periods of vertically mixed water, the more diffuse nature of the IRS model enables freshwater transport farther (west) offshore than in reality, in turn under predicting the density of the western boundary values for the LB model. A bias in the initial IRS model salinity acts to improve the simulation during these winter mixed conditions.

In May and July the water column experiences greater vertical stratification. In May (Fig. 11) there is a clear freshwater plume extending across the transect. Both models are able to capture this pattern, but there are clear differences in the density values over the transect. 
The LB model with unbiased IRS boundary conditions (LB2, Fig. 11d) clearly produces results that most closely match the observations. In July (Fig. 12) the brackish coastal waters are observed to cause stratification slightly offshore from the coast. The stratification becomes confined to the surface layer further offshore at the western extent of the transect. The models are generally able to capture the brackish coastal water and stratification, but simulate vertically well-mixed water offshore. The density values and position of strongest stratification show some error. In this period the biased IRS model performs best (IRS2, Fig. 10c). The fact LB2 (Fig. 12c) is more accurate than LB1(Fig. 12e) again suggests that the position of the offshore boundary in the nested LB model relative to the ROFI expansion in the IRS model is important for accurate simulation of the ROFI expansion in the high resolution model. Although POLCOMS has limited capability in representing the plume structure, it does capture the general variability in the location and depth of the plume under the different conditions during the months of May and July at both model resolutions. These results show that POLCOMS is able to broadly capture stratification (May and July) and vertically mixing (January) of the water column in response to the physical forcing. However, these observations prevent the assessment of POLCOMS' capability at simulating when the onset and breakdown of the stratification takes place, which could have possible consequences to the transport of material.

In general (Fig. 9), no single model setup universally improves the model performance for all observations during all three cruise periods. The biased initial conditions in the IRS model (IRS2) perform better than the unbiased setup (IRS1) in January (day 10). This in turn has the same impact on the LB model with the biased IRS boundary condition setup (LB1) performing better than the unbiased setup (LB2). After the upwelling event (day 81, in March) there is a reversal in the model performance. In May (day 134) IRS1 and LB2 
perform better than IRS2 and LB1. In July (day 212) there is no clear link between the model performance and nesting. IRS2 and LB2 perform the best. The improved IRS performance for IRS1 in May is due to the cruise occurring at a period when there is a dip in the observed salinity values (day 134, Fig. 5). The model response to this short-term fluctuation is under predicted causing temporary positioning of the unbiased simulation closer to the observations. The step change in the LB model performance after the March upwelling event agrees with the fixed mooring analysis (Fig. 6).

\section{Discussion}

This study shows how downscaling via model nesting is important to reproduce ROFI dynamics and to resolve frontal features within an operational suite. Nesting reduces erroneous export of freshwater offshore due to numerical diffusion related to the grid resolution. The high $(180 \mathrm{~m})$ resolution LB model applied here is able to resolve the ROFI's internal structure, but the model accuracy is dictated by the offshore boundary conditions. Varied boundary conditions are provided by a $1.8 \mathrm{~km}$ IRS model setup that uses different initial conditions. Simulations with varied boundary conditions (shown) and modified freshwater inflow (shown by Norman et al., 2014d) identified that it is the offshore (boundary) conditions that have most control on the offshore export of freshwater in the LB model. Simulations with the LB model that considered: relocating the rivers; increasing the river channel depth to ensure continuous unrestricted flow to the estuary mouth; increased river flow; and modified model parameter settings, only had localised estuarine impact. The rapid convergence of the biased initial salinity LB simulations after the coastal upwelling event (day 81, Fig. 7) suggests that the baroclinic transport processes during such an event can reset a ROFI if perturbed by external (offshore or atmospheric) conditions, thus restoring equilibrium conditions more rapidly than the flushing time of the coastal system. 
In POLCOMS the daily-average temperature and salinity fluxes are imposed at the offshore boundary. This should be acceptable since the boundary is beyond the coastal front where the water is homogeneous or has weak horizontal gradients during periods of weak tidal straining (typically an excursion of $<10 \mathrm{~km}$ ). We find that although the offshore boundary is some distance beyond the coastal front (Fig. 8b), this location can still experience weak horizontal salinity gradients in the IRS model providing the boundary conditions to the LB model. This result suggests that the LB model boundaries are too close to the ROFI due the numerical diffusion of the IRS model exporting freshwater too far offshore in extreme conditions, causing boundary conditions that are temporarily too fresh. However, a larger high resolution domain or an additional intermediate $(\sim 360 \mathrm{~m})$ grid nesting would start to cause unfeasible computational costs for operational forecasting. Thus, unstructured regional models with increasing coastal grid resolution are suggested as a more appropriate approach than nested modelling systems for large ROFIs within hypertidal regions. The large annual variability in the ROFI extent could also potentially benefit from mesh evolving algorithms (e.g., Araújo et al., 2013) to further improve model efficiency, with a time-evolving high concentration of grid nodes over the ROFI.

Resolution of the IRS initial conditions is important for a more accurate response of the water column structure to the physical forcing within the ROFI domain, thus are important for more accurate boundary forcing. Initial conditions are typically imposed by a coarser model that forms an initial simulation within which a higher resolution grid can be nested. In the operational system applied here the $12 \mathrm{~km}$ AMM imposes climatological river discharge at 0 psu with some inflows positioned within Liverpool Bay due to coastline resolution. In consequence, the salinity conditions within Liverpool Bay are too fresh, due to both the river 
source positioning and numerical diffusion introduced by the grid resolution (Fig. 3).

Initialising the IRS model with the preoperational IRS model of the same resolution improves the simulation during the initial months of stormier conditions. The more noticeable impact at Site B (Fig. 5b, and also in turn Fig.6b) suggests the improvement is due to a reduction in freshwater export offshore. Even though the preoperational IRS model more accurately positions the rivers, some error still remains with the implementation of climatological forcing and a $10 \mathrm{~m}$ minimum depth preventing accurate coastal bathymetry influencing the estuarine out flows. At $1.8 \mathrm{~km}$ resolution the imposed salinity 0 psu or 20 psu has little impact (Norman et al., 2014a). Using the improved IRS model initialisation to prescribe the boundary condition to the LB model modifies not only the long-term changes, but also the short-term straining of the horizontal gradients. This is due to the initial structure of the water column having a long-term influence on the IRS model results and in turn the LB model, through boundary forcing. An accurate initial water column structure is clearly important at the regional (shelf sea) scale, influencing the annual variability in response to short-term variability in forcing from winds and tide in both the model itself and any nested applications. Small modifications within the IRS model have an important impact on the ability of the LB model to simulate the annual ROFI dynamics. These results show that in a nested simulation downscaling cannot be relied upon to generate the best simulation. Even in an energetic environment with low freshwater inflow the offshore boundary conditions are found to have greatest influence on the accuracy of the local high resolution simulation.

By implementing a bias in the initial salinity conditions a noticeable difference in the response of both models occurs. The IRS model is influenced for the full year (IRS2), while the LB model (LB 3 \& LB4) reverts to the nonbiased (LB2) results after a few months. This shows that a perturbation within the ROFI is quickly restored back to equilibrium with the 
offshore (boundary) conditions. The change to the IRS model has a more permanent influence on the offshore waters, which are uninfluenced by coastal inflow within the larger domain. The biased offshore waters are therefore able to have a continued influence on the coastal ROFI restricting its offshore expansion. The offshore movement of the ROFI following the winter period, day 81-82 (Fig. 2), marks a step change in the error within the LB model in response to the boundary forcing. This shows the control of offshore salinity on the horizontal gradients across the Liverpool Bay ROFI. Before the upwelling event (day 81) enabling the ROFI expansion, LB1 is better and after the event LB2 is better. Improving the initial conditions within the IRS model (IRS3) resulted in an improvement in the LB model (LB5), particularly during the initial months where performance was poor using LB2. This demonstrates the importance of accurate initial conditions being implemented throughout the nested system. The small modification in the initial conditions made a noticeable improvement in the simulation of the upwelling event (compare LB5 and LB2 in Fig. 6). This shows the value of regional operational models in providing boundary and initial conditions. If the preoperational system applied could have used more realistic river inflow, rather than climatology, a more accurate response to the initial windy conditions and representation of the upwelling event may have been achieved.

These results suggest there are two distinct ROFI structures during 2008. Prior to the coastal upwelling event, which is able to move the frontal position an extensive distance offshore (influencing Site B), the water column was vertically well-mixed or weakly stratified towards the coast and of higher salinity. After this event stratification is observed and there is a steady increase in salinity (density) across the ROFI. It is suggested that atypical export of freshwater to such a distance offshore caused a more persistent change in the ROFI dynamics than usual, preventing rapid recovery. After the upwelling event the tidal influence on the 
time-varying density is greater. Such variation is typical at Site A, but after the event Site B also shows short-term variability and stronger stratification. Prior to the event weak stratification only occurred during the high river discharge periods at this offshore site (see Norman et al., 2014c).

Without observations at the start of the year it cannot be stated that the model performs poorly during the initial winter period. Continuing this simulation into 2009 would not confirm the model's capability at simulating the winter. This is because the initial conditions in 2008 are very similar to the final conditions in 2008, suggesting the period of high salinities in the early part of 2008 are in response to the wind conditions and that either the model response is not rapid enough at the resolution of the IRS model, or that the initial conditions obtained from the preoperational model need to have higher accuracy. The model suggests the initial salinities were lower than first observed and that a certain combination of conditions (winds acting on a certain horizontal density gradient) during the initial period caused the higher salinities within the first few months. It is suggested that this early increase in salinity is under predicted by the model, due to error in the initial salinity gradients, rather than the initial value of the salinities, and that this also prevents the rapid reduction in salinity as the system responds to the release of the coastally trapped freshwater around day 81 .

From these results it is suggested that the wind direction is a dominant control on the offshore excursion of the front. Initial strong south to westerly winds during winter storms cause downwelling and vertical mixing causing the initial period of high salinities. After the upwelling event the predominant weaker winds from south to westerly directions slowly restore these higher salinities. High river flow events later in the year (e.g., day 250) are able to influence Site A (reducing the salinity), but unless coincidental with appropriate wind 
directions seem to have limited influence at Site B. There are occasions late in the year when freshening events are evident at both sites. These seem to be related to winds that promote upwelling along the English coast. Events that only influence Site A (e.g., day 250, Fig. 2) are associated with turning wind directions that cause winds with a northerly component for a short period. This case study suggests upwelling seems to be the main driver enabling the export of freshwater offshore, even within a region of strong tidal influence.

\section{Conclusion}

Application of POLCOMS to the Liverpool ROFI has demonstrated the importance of accurately representing the initial structure of the water column and the boundary conditions when simulating the dynamics of a large ROFI. It is shown that increased model resolution is able to improve the frontal structure, but the accuracy is determined by the offshore boundary conditions applied to the high resolution nested model. In this application we find for the coarse $(1.8 \mathrm{~km})$ model that the initial conditions are most influential. The initial structure of the water column influences the ROFI dynamics and any adjustment, such as a bias in physical properties (salinity in this case), is persistent for an annual cycle. This is a consequence of the permanent change in the offshore waters uninfluenced by the ROFI having a controlling influence on the ROFI expansion away from the coast. For a nested high resolution $(180 \mathrm{~m})$ model, that only represents the ROFI, the boundary conditions are more influential. A change in the initial conditions is only found to persist for a few months until the model is able to revert to a state of equilibrium with the boundary conditions. A ROFI is therefore able to respond to perturbations in the system over a short-time period due to the dynamically changing vertical mixing and re-stratification of the system, while it is constrained by a perturbation in the offshore conditions. 
Sensitivity analysis has found that changes in the estuarine water source were uninfluential on the offshore extent of the freshwater export, while the nested setup was a major influence controlling the nearshore gradients. It is clear that consideration must be given to the numerical grid resolution to accurately represent a ROFI. Numerical diffusion at $1.8 \mathrm{~km}$ can cause a ROFI to be too dispersed. Introducing a bias to compensate for this locally improved accuracy at the coarse model scale, but was shown to have an adverse effect on the offshore boundary forcing to a local nested model covering the ROFI. This is a consequence of the nested model removing error due to numerical diffusion and requiring the highest accuracy in boundary conditions offshore from the ROFI. To improve the accuracy of the prescribed boundary conditions the best available initial conditions are required at the shelf sea scale. In this case we initialize the $1.8 \mathrm{~km}$ IRS model from a preoperational $12 \mathrm{~km}$ AMM, which poorly resolves the river sources and experiences error from numerical diffusion, and a preoperational version of the IRS model. The latter enabling improved time variation in the boundary conditions over the annual period. In the absence of an operational model at a similar resolution, model initialisation can be problematic due to the use of data from a coarser model nest and the need for long spin-up times to achieve an equilibrium state with boundary forcing.

\section{Acknowledgements}

This research has been completed as part of the iCOASST (NERC grant NE/J005444/1) and ARCoES (EPSRC, ARCC-CN programme grant EP/I035390/1) projects, and through NERC National Capability funding to the NOC. The observations for validation were obtained from the Liverpool Bay Coastal Observatory along with the conditions for the Irish Sea model setup. River data have been obtained from CEH for available EA gauging stations. The UK Met Office is thanked for providing the atmospheric forcing for all the nested models and the 
Atlantic Margin boundary conditions to the Coastal Observatory preoperational modelling suite used in this application.

\section{References}

Araújo, M.A.V.C., Mazzolari, A., Trigo-Teixeira, A. 2013. An object oriented mesh generator: application to flooding in the Douro estuary. Journal of Coastal Research, Special Issue 65 (1), 642-647.

Amoudry, L.O., Ramirez-Mendoza, R., Souza, A.J., Brown, J.M. 2014. Modelling-based assessment of suspended sediment dynamics in a hypertidal estuarine channel. Ocean Dynamics, 64 (5), 707-722.

Bolaños, R., Brown, J.M., Amoudry, L.O., Souza, A.J., 2013. Tidal, Riverine, and Wind Influences on the Circulation of a Macrotidal Estuary. Journal of Physical Oceanography, 43 (1), 29-50.

Bowden, K.F., 1980. Chapter 12 Physical and Dynamical Oceanography of the Irish Sea, In: F.T. Banner, M.B. Collins and K.S. Massie, Editor(s), Elsevier Oceanography Series, Elsevier, 24 (Part B), 391-413.

Bricheno, L.M., Wolf, J.Brown, J.M., 2014. Impacts of high resolution model downscaling in coastal regions. Continental Shelf Research, 87, 7-16.

Brown, J.M., 2010 A case study of combined wave and water levels under storm conditions using WAM and SWAN in a shallow water application. Ocean Modelling, 35 (3), 215 229. 
Brown, J.M., Amoudry, L.O., Mercier, F.M., Souza, A.J., 2013. Intercomparison of the Charnock and COARE bulk wind stress formulations for coastal ocean modelling, Ocean Science 9 (4), 721-729.

Brown, J.M., Amoudry, L.O., Souza, A.J., Rees, J., 2015. Fate and pathways of dredged estuarine sediment spoil in response to variable sediment size and baroclinic coastal circulation, Journal of Environmental Management 149, 209-221.

Brown, J.M. Wolf, J. 2009. Coupled wave and surge modelling for the eastern Irish Sea and implications for model wind-stress. Continental Shelf Research, 29 (10), 1329-1342.

Brown, J.M., Bolaños, R., Wolf, J., 2011. Impact assessment of advanced coupling features in a tide-surge-wave model, POLCOMS-WAM, in a shallow water application. Journal of Marine Systems, 87 (1), 13-24.

Canuto, V.M., Howard, A., Cheng, Y., Dubovikov, M.S., 2001. Ocean turbulence. Part 1: one-point-closure model - momentum and heat vertical diffusivities. Journal of Physical Oceanography 31, 1413-1426.

Charnock, H., 1955. Wind-stress on a water surface, Quarterly Journal of Royal Meteorological Society 81, 639-640, 1955.

Cooper, N., Pontee, N., 2006. Appraisal and evolution of the littoral 'sediment cell' concept in applied coastal management: experiences from England and Wales. Ocean and coastal management, 49, 498-510.

Colella, P., Woodward, P.R., 1984. The Piecewise Parabolic Method (PPM) for gasdynamical situations, Journal of Computational Physics 54, 174-201. 
Dabrowski, T. Hartnett, M. Olbert, A.I., 2010. Influence of seasonal circulation on flushing of the Irish Sea. Marine Pollution Bulletin, 60 (5), 748-758.

Dabrowski, T., Hartnett, M., Olbert, A.I., 2012. Determination of flushing characteristics of the Irish Sea: A spatial approach. Computers \& Geosciences, 45, 250-260.

de Boer, G.J., Pietrzak, J.D., Winterwerp, J.C., 2006. On the vertical structure of the Rhine region of freshwater influence. Ocean Dynamics. 56, (3-4), 198-216.

de Boer, G.J., Pietrzak, J.D., Winterwerp, J.C., 2009. SST observations of upwelling induced by tidal straining in the Rhine ROFI. Continental Shelf Research, 29 (1), 263-277.

Duran-Matute, M., Gerkema, T., de Boer, G. J., Nauw, J. J., and Gräwe, U., 2014. Residual circulation and freshwater transport in the Dutch Wadden Sea: a numerical modelling study. Ocean Sciences, 10, 611-632.

Fairall, C.W., Bradley, E.F., Hare, J.E., Grachev, A.A., Edson, J.B., 2003. Bulk parameterization of air-sea fluxes: Updates and verification for the COARE algorithm, Journal of Climate 16, 571-591.

Fofonoff, N.P., Millard Jr, R.C., 1983. Algorithms for computation of fundamental properties of seawater. Unesco technical papers in marine science, 44, 1-53.

Fischer, H.B., 1976. Mixing and dispersion in estuaries. Annual Review of Fluid Mechanics 8, 107-133.

Garvine, R.W., 1987. Estuary Plumes and Fronts in Shelf Waters: A Layer Model. Journal of Physical Oceanography 17 (11), 1877-1896.

Greenwood, N., Hydes, D.J., Mahaffey, C., Wither, A., Barry, J., Sivyer, D., Pearce, D.J., Hartman, S.E., Andres, O., Lees, H.E., 2011. Spatial and temporal variability in 
nutrient concentrations in Liverpool Bay, a temperate latitude region of freshwater influence. Ocean Dynamics 61, 2181-2199.

Holt, J., James, I.D., 2001. An s-coordinate model of the European continental shelf. Part 1: model description and density structure. Journal of Geophysical Research 106(C7), $14015-14034$.

Holt, J.T., Proctor, R., 2008. The seasonal circulation and volume transport on the northwest European continental shelf: a fine-resolution model study. Journal of Geophysical Research, 113 (C6), C06021.

Holt, J.T., Proctor, R., 2003. The role of advection in determining the temperature structure of the Irish Sea. Journal of Physical Oceanography, 33, 2288-2306.

Holt, J.T., Umlauf, L., 2008. "Modelling the tidal mixing fronts and seasonal stratification of the Northwest European Continental shelf," Continental Shelf Research 28 (7), 887 903.

Hopkins, J., Polton, J.A., 2012. Scales and structures of frontal adjustment and freshwater export in a region of freshwater influence. Ocean Dynamics 62, 45-62.

Howarth, M.J, Balfour, C.A., Player, R.J., Polten, J.A., 2014. Assessment of coastal density gradients near a macro-tidal estuary: Application to the Mersey and Liverpool Bay. Continental Shelf Research 87, 73-83

Howarth, M.J., O’ Neill, C.K., Palmer, M.R., 2010. The Liverpool Bay Coastal Observatory, Geophysical Research Abstracts, 12, OS2, EGU2010-3244, 2pp.

Howarth, J., Palmer, M., 2011. The Liverpool Bay Coastal Observatory. Ocean Dynamics 61, 1917-1926. 
James, I.D., 1996. Advection schemes for shelf sea models, Journal of Marine Systems 8, $237-254$.

James, I.D., 1997. A numerical model of the development of anticyclonic circulation in a gulf-type region of freshwater influence, Continental Shelf Research 17, 1803-1816.

Marsh, T.J., Sanderson, F.J., 2003. Derivation of Daily Outflows from Hydrometric Areas. National River Flow Archive. CEH Wallingford report July 2003, 14pp.

Nakada, S., Ishikawa, Y., Awaji, T., In, T., Shima, S., Nakayama, T., Isada, T., Saitoh, S.-I., 2012. Modeling runoff into a Region Of Freshwater Influence for improved ocean prediction: Application to Funka Bay. Hydrological Research Letters 6, 47-52.

Norman, D., Brown, J.M., Amoudry L.O., Souza A.J., 2014a. POLCOMS sensitivity analysis to river temperature proxies, surface salinity flux and river salinity in the Irish Sea, National Oceanography Centre Internal Document, National Oceanographic Library, Southampton, UK, No. 08, 22pp.

Norman, D., Brown, J.M., Amoudry L.O., Souza A.J., 2014b. Was 2008 a typical year in Liverpool Bay? National Oceanography Centre Internal Document, National Oceanographic Library, Southampton, UK, No. 09, 19pp.

Norman, D., Brown, J.M., Amoudry L.O., Souza A.J., 2014c. Processes controlling stratification in Liverpool Bay. National Oceanography Centre Internal Document, No. $10,18 \mathrm{pp}$

Norman, D., Brown, J.M., Amoudry L.O., Souza A.J., 2014d. Investigation of the Liverpool Bay mixing front using POLCOMS. National Oceanography Centre Internal Document, National Oceanographic Library, Southampton, UK, No. 11, 38pp. 
O'Neill, C.K., Polton, J.A., Holt, J.T., O'Dea, E.J., 2012. Modelling temperature and salinity in Liverpool Bay and the Irish Sea: Sensitivity to model type and surface forcing. Ocean Science 8 (5), 903-913.

MacCready, P., Geyer, W.R., 2010. Advances in estuarine physics. Annual Review of Marine Science 2, 35-58.

Palmer, M.R., Polton, J.A., 2011. A strain-induced freshwater pump in the Liverpool Bay ROFI. Ocean Dynamics 61, 1905-1915.

Panton, A., Mahaffrey, C., Greenwood, N., Hopkins, J., Montagnes, D., Sharples, J., 2012. Short-term and seasonal variation in metabolic balance in Liverpool Bay, Ocean Dynamics 62 (2), 295-306.

Periáñez, R., 2005. Modelling the transport of suspended particulate matter by the Rhone River plume (France). Implications for pollutant dispersion. Environmental Pollution $133(2), 351-364$.

Phelps, J.J.C., Polton, J.A., Souza, A.J., Robinson, L.A., 2013. Hydrodynamic timescales in a hyper-tidal region of freshwater influence. Continental Shelf Research, 63, 13-22.

Polton, J.A., Palmer, M.R., Howarth M.J., 2011. Physical and dynamical oceanography of Liverpool Bay. Ocean Dynamics 61, 1421-1439.

Polton, J.A., Palmer, M.R., Howarth M.J., 2013. The vertical structure of time-mean estuarine circulation in a shallow, rotating, semi-enclosed coastal bay: A Liverpool Bay case study with application for monitoring. Continental Shelf Research 59, 115-126.

Ramirez-Mendoza, R., Souza, A.J., Amoudry, L.O., 2014. Modeling flocculation in a hypertidal estuary. Ocean Dynamics, 64 (2), 301-313. 
Reffray, G., Fraunié, P., and Marsaleix, P., 2004. Secondary flows induced by wind forcing in the Rhône region of freshwater influence. Ocean Dynamics 54 (2), 179-196.

Sánchez-Arcilla, A., Wolf, J., Monbaliu, J., 2014. Oceanography at coastal scales: Introduction to the special issue on results from the EU FP7 FIELD_AC project. Continental Shelf Research, 87, 1-6.

Scully, M.E., Friedrichs, C., Brubaker, J., 2005. Control of estuarine stratification and mixing by wind-induced straining of the estuarine density field. Estuaries 28 (3), 321-326.

Simpson, J.H., Brown, J., Matthews, J., Allen, G., 1990. Tidal straining, density currents, and stirring in the control of estuarine stratification. Estuaries 13, 125-132.

Simpson, J.H., Bos, W.G., Schirmer, F., Souza, A.J., Rippeth, T.P., Jones, S.E., Hydes, D., 1993. Periodic stratification in the Rhine ROFI in the North Sea. Oceanologica Acta 16 (1), 23-32.

Simpson, J. H., Bowers, D., 1981. Models of stratification and frontal movements in shelf seas, Deep Sea Research Part A, 28, 727-738.

Souza, A.J., Lane, A., 2013. Effects of freshwater inflow on sediment transport. Journal of Operational Oceanography 6 (1), 27-31.

Umlauf, L., Burchard, H., Bolding, K., 2005. General ocean turbulence model: Source code documentation. Baltic Sea Research Institute Warnemünde Technical Report 63, 346 pp.

Yamashita, Y., Panton, A., Mahaffey, C., Jaffe, R., 2010. Assessing the spatial and temporal variability of dissolved organic matter in Liverpool Bay using excitation-emission matrix fluorescence and parallel factor analysis. Ocean Dynamics 61 (5), 569-579. 
Young, E.F., Holt, J.T., 2007. Prediction and analysis of long-term variability of temperature and salinity in the Irish Sea, Journal Geophysical Research 112, C01008.

Warner, J.C., Armstrong, B., He, R., Zambon, J.B., 2010. Development of a Coupled OceanAtmosphere-Wave-Sediment Transport (COAWST) Modeling System, Ocean Modelling, 35 (3), 230-244.

Whitney, M.M., and Garvine, R.W., 2005. Wind influence on a coastal buoyant outflow. Journal of Geophysical Research 110:C03014. doi:10.1029/2003JC002261

Willmott, C.J., 1981. On the validation of models. Physical Geography 2 (2), 184-194.

Wolf, J., Brown, J.M., Howarth, M.J., 2011. The wave climate of Liverpool Bay observations and modelling. Ocean Dynamics 61 (5), 639-665. 


\section{Figures and tables}

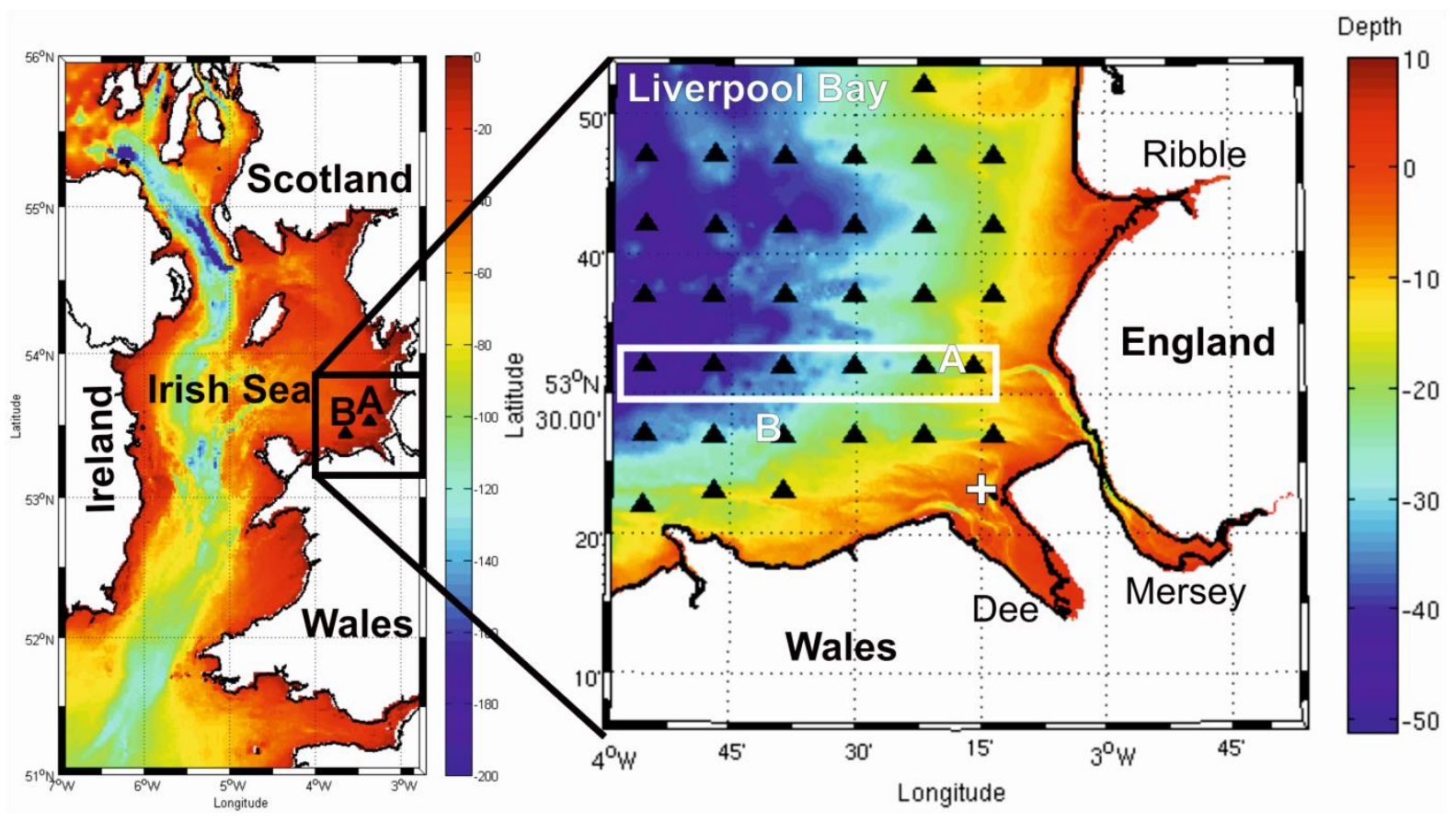

Fig. 1. The bathymetry ( $\mathrm{m}$ below mean tidal level) for the nested Irish Sea (IRS) and

Liverpool Bay (LB) model domains. The outer edge marks the model boundaries with the fixed mooring sites (A and B), CTD survey grid marked by triangular symbols and Dee met station marked by a cross. 


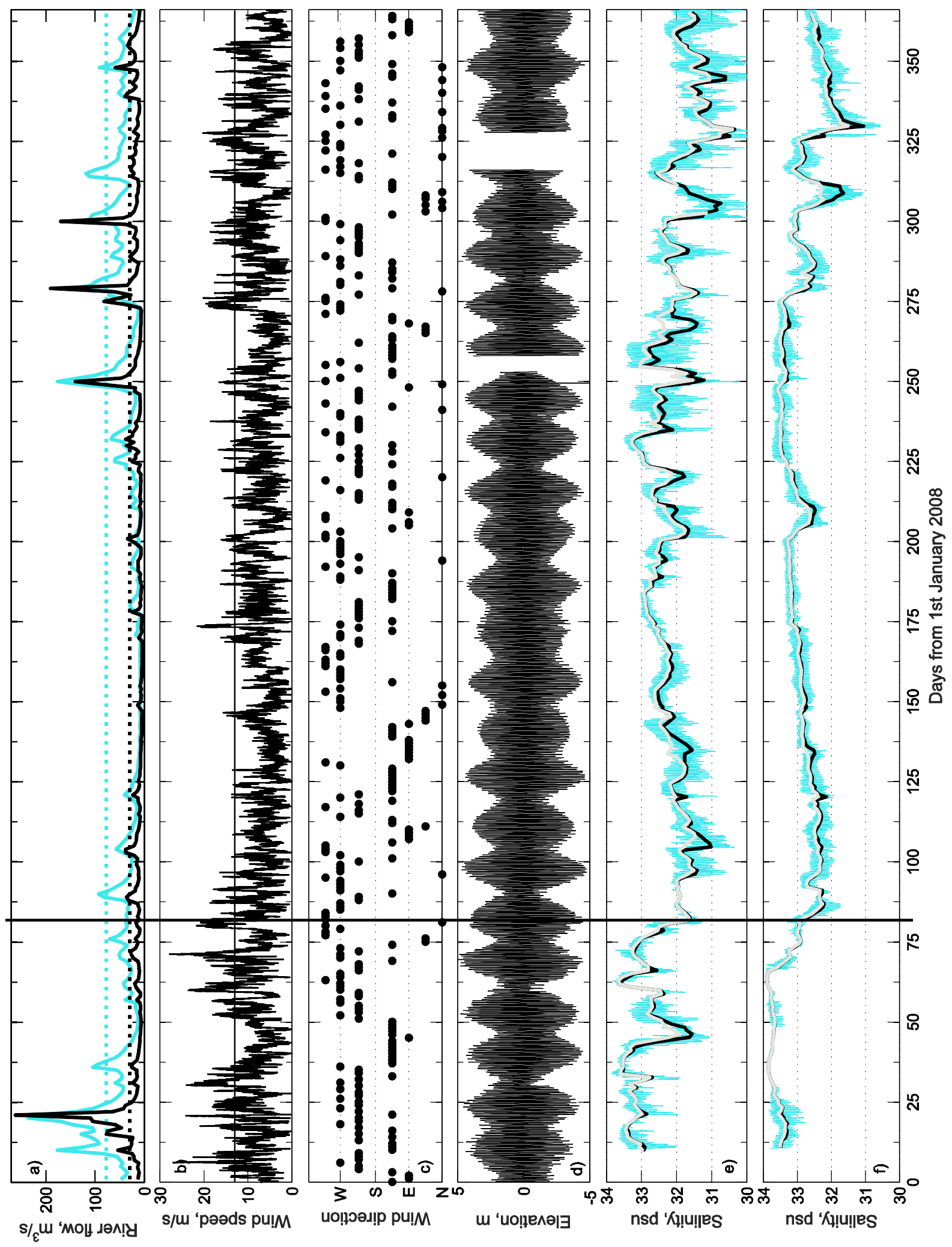

Fig. 2. The conditions during the study period. a) Daily mean and $90^{\text {th }}$ percentile river discharge for the Dee (higher flow, lighter line) and Mersey (lower flow, darker line) gauging stations. b) Hourly and $90^{\text {th }}$ percentile wind speeds showing calm and stormy 
periods. c) Dominant daily (modal class) wind direction from the north $\left(337.5^{\circ}<\theta \leq 22.5^{\circ}\right)$, northeast $\left(22.5^{\circ}<\theta \leq 67.5^{\circ}\right)$, east $\left(67.5^{\circ}<\theta \leq 112.5^{\circ}\right)$, southeast $\left(112.5^{\circ}<\theta \leq 157.5^{\circ}\right)$, south $\left(157.5^{\circ}<\theta \leq 202.5^{\circ}\right)$, southwest $\left(202.5^{\circ}<\theta \leq 247.5^{\circ}\right)$, west $\left(247^{\circ}<\theta \leq 292.5^{\circ}\right)$ and northwest $\left(292.5^{\circ}<\theta \leq 337.5^{\circ}\right)$, the most frequent direction being shown as this is most important for the movement of the front. d) Tidal elevation at Liverpool. Coastal salinity at $5 \mathrm{~m}$ (variable line) and the 25 hour running mean at $5 \mathrm{~m}$ (higher lighter line) and10 m (lower darker line) below the surface for e) Site A and f) Site B. The vertical line represents a time at which low salinities are reached at Site A (day 81) following an upwelling event; there is a lag at Site B. This marks a change in the model's response to the forcing conditions.
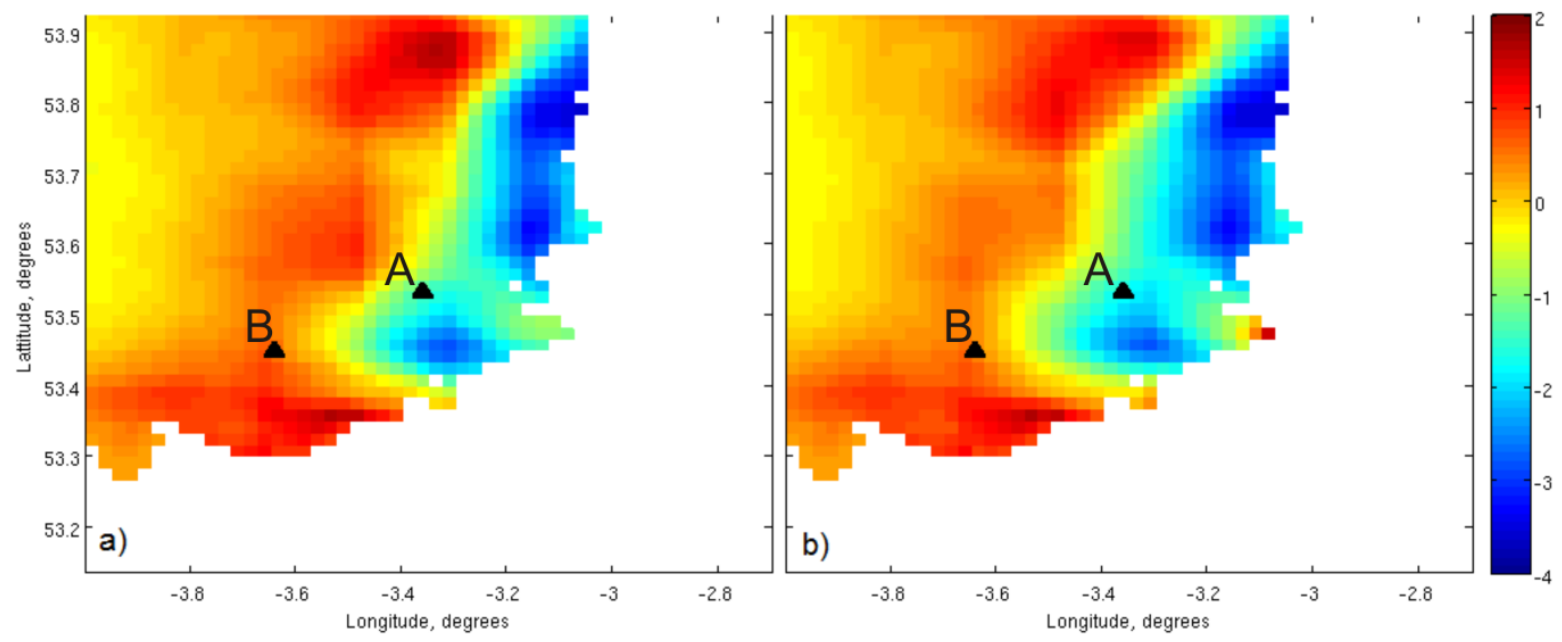

Fig. 3. The different in salinity (psu) between the unbiased (IRS1) and unbiased high resolution (IRS3) initial conditions: a) near the bed and b) near the surface. 
Site A
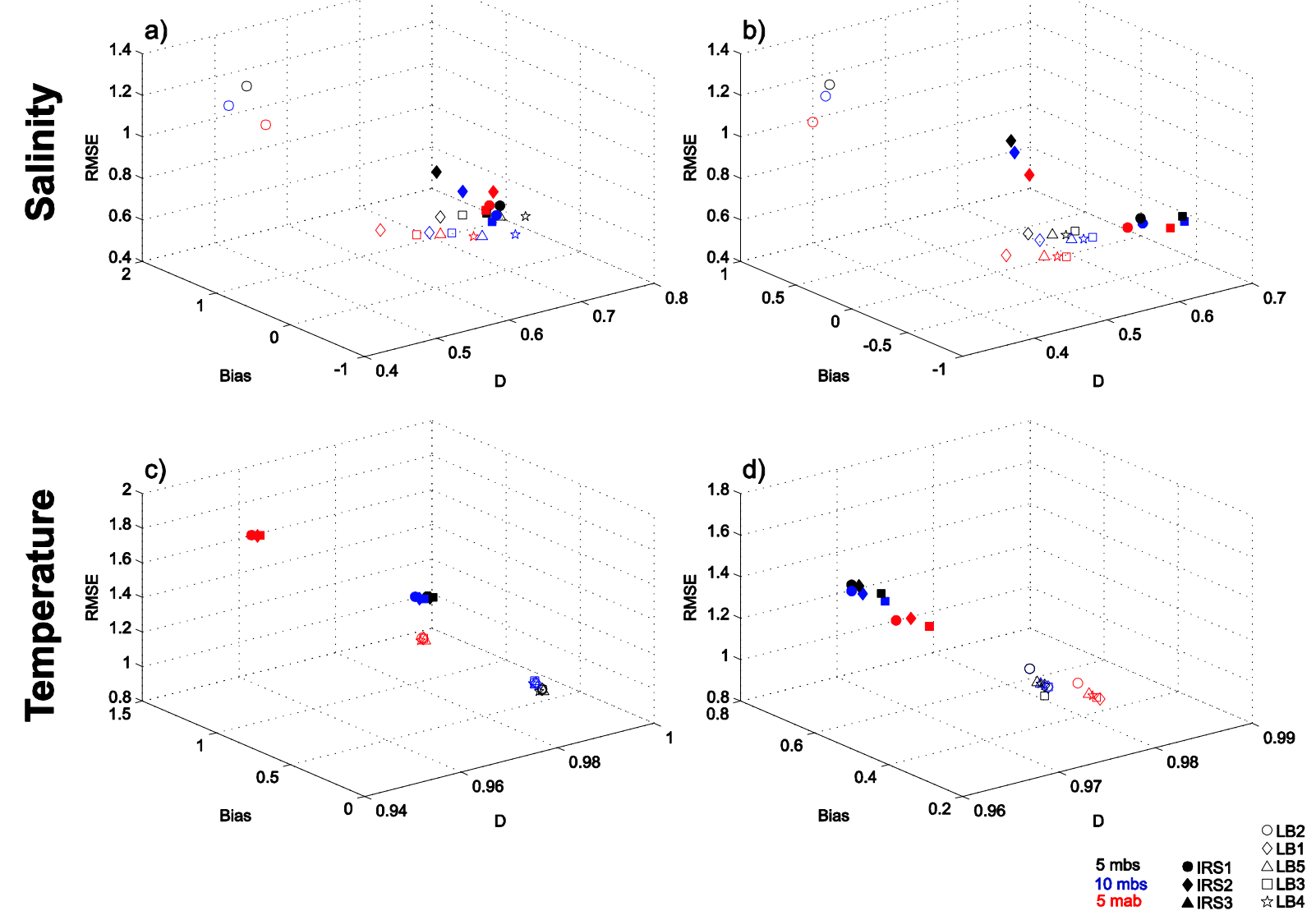

Fig. 4. Validation metrics, Eqs. 1-3, for the IRS (Table 1, filled symbols) and LB (Table 2, unfilled symbols) model simulations at the 3 levels available (either m below surface, mbs, or $\mathrm{m}$ above bed, msb differentiated by colour) at the fix mooring Sites A (panel a \& c) and B (panel b \& d). Error metrics are presented for the salinity (psu, panel a \& b) and temperature $\left({ }^{\circ} \mathrm{C}\right.$, panel $\left.\mathrm{c} \& \mathrm{~d}\right)$. The metrics take the same units as the parameters apart from the model skill, which is non-dimensional. 

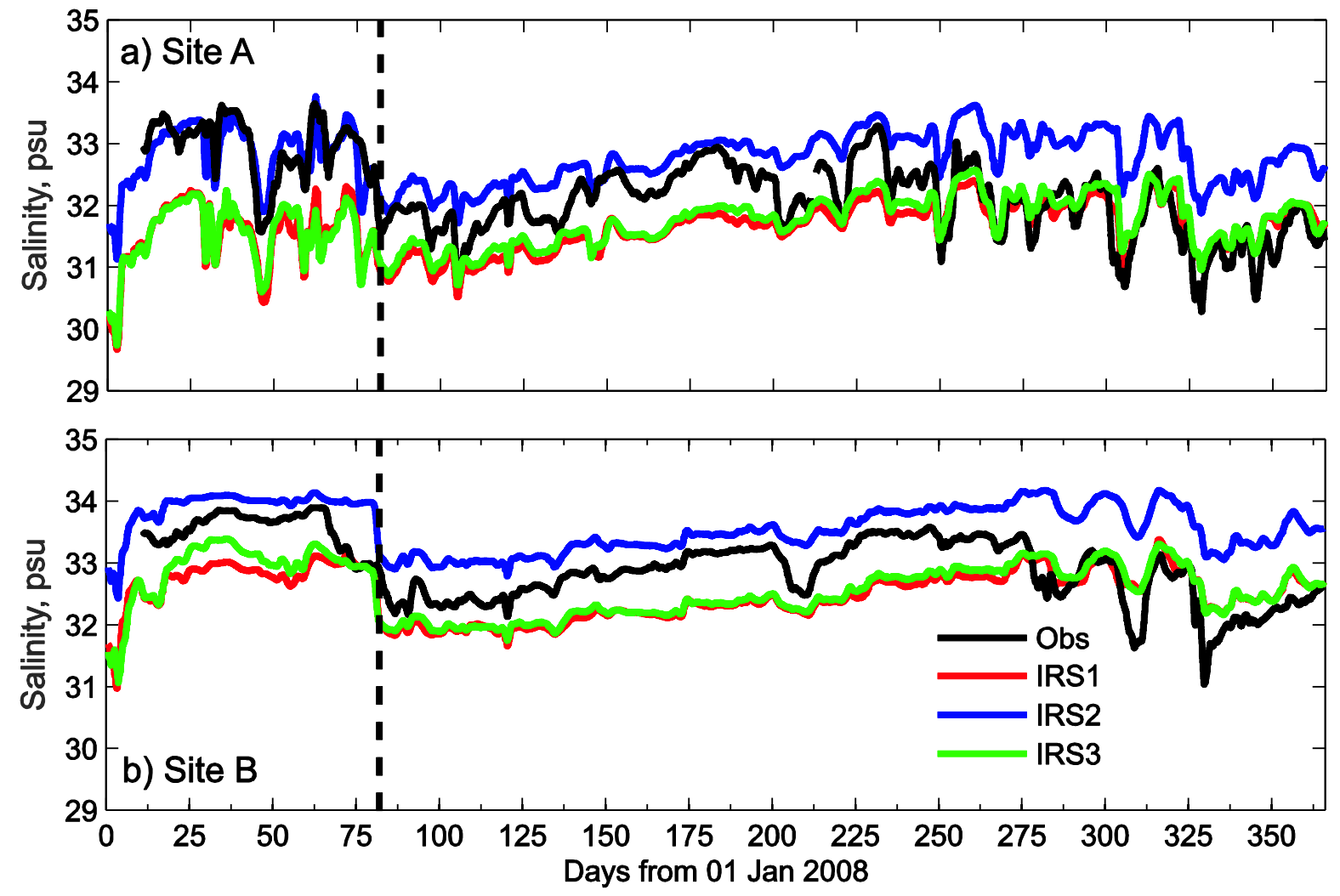

Fig. 5. The annual 200825 hour running mean in salinity at $5 \mathrm{~m}$ below the surface at mooring

Site A (a) and Site B (b) for each Irish Sea (IRS) model simulation (Table 1) and the observations. The vertical dashed line indicates the time of minimum salinity observed at Site A after the upwelling event (day 81) that causes the sudden expansion of the ROFI offshore. 

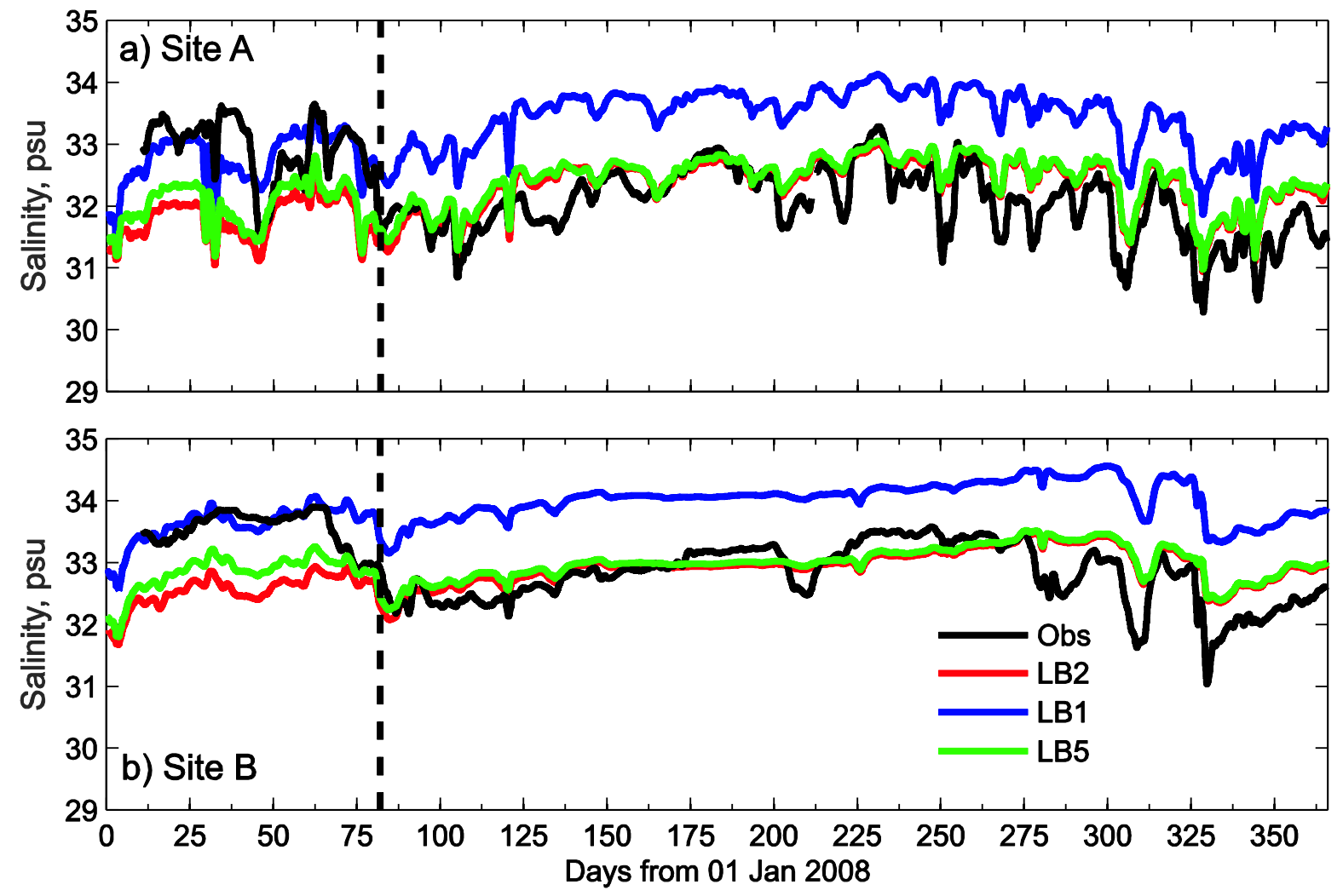

Fig. 6. The annual 200825 hour running mean in salinity at $5 \mathrm{~m}$ below the surface at mooring Site A (a) and Site B (b) for the Liverpool Bay (LB) model simulations (Table 2) with variable IRS boundary forcing and the observations. The vertical dashed line indicates the time of minimum salinity observed at Site A after the upwelling event (day 81) that causes the sudden expansion of the ROFI offshore. 

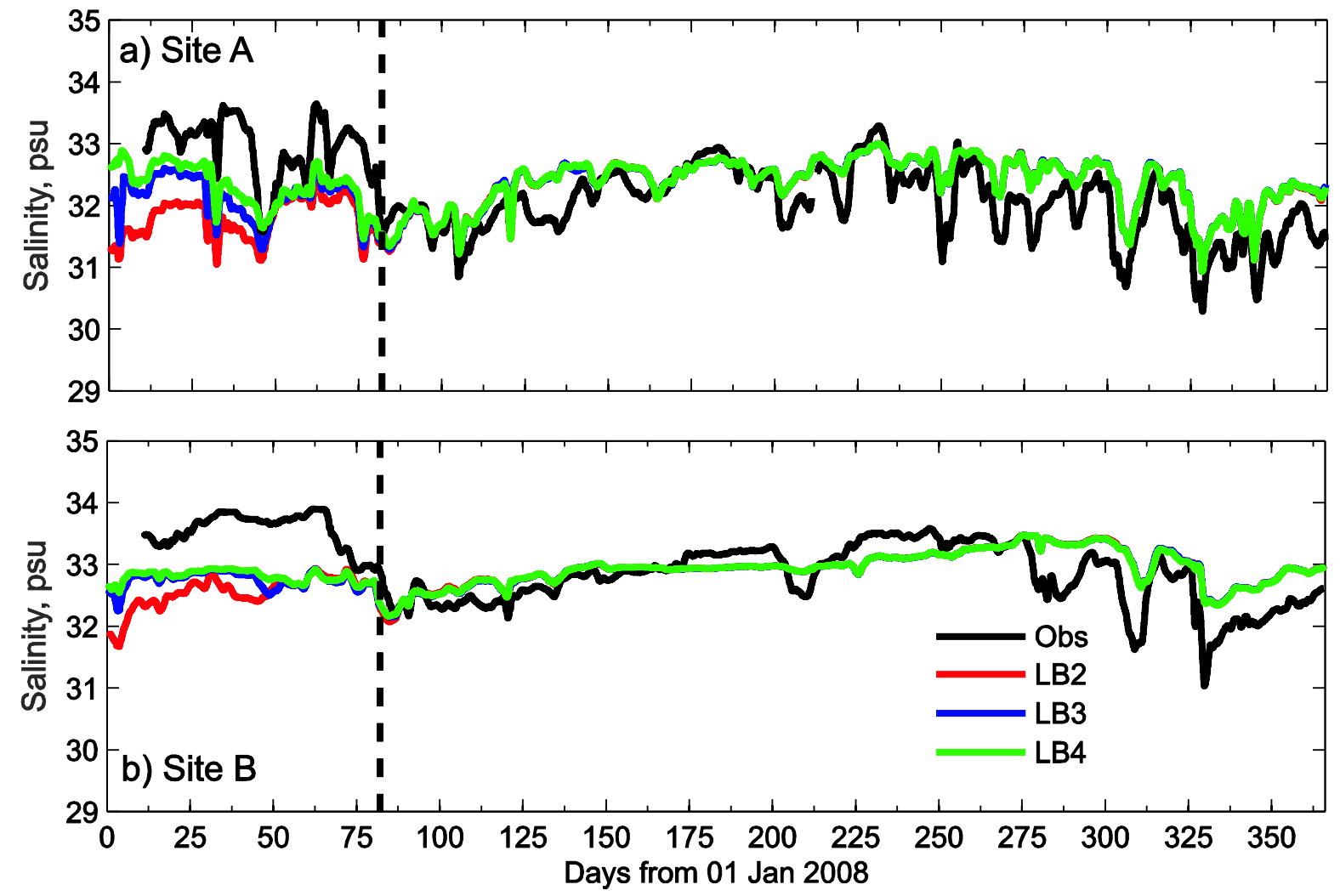

Fig. 7. The annual 200825 hour running mean in salinity at $5 \mathrm{~m}$ below the surface at mooring

Site A (a) and Site B (b) for the Liverpool Bay (LB) model simulations (Table 2) with locally biased initial conditions and the observations. The vertical dashed line indicates the time of minimum salinity observed at Site A after the upwelling event (day 81) that causes the sudden expansion of the ROFI offshore. 

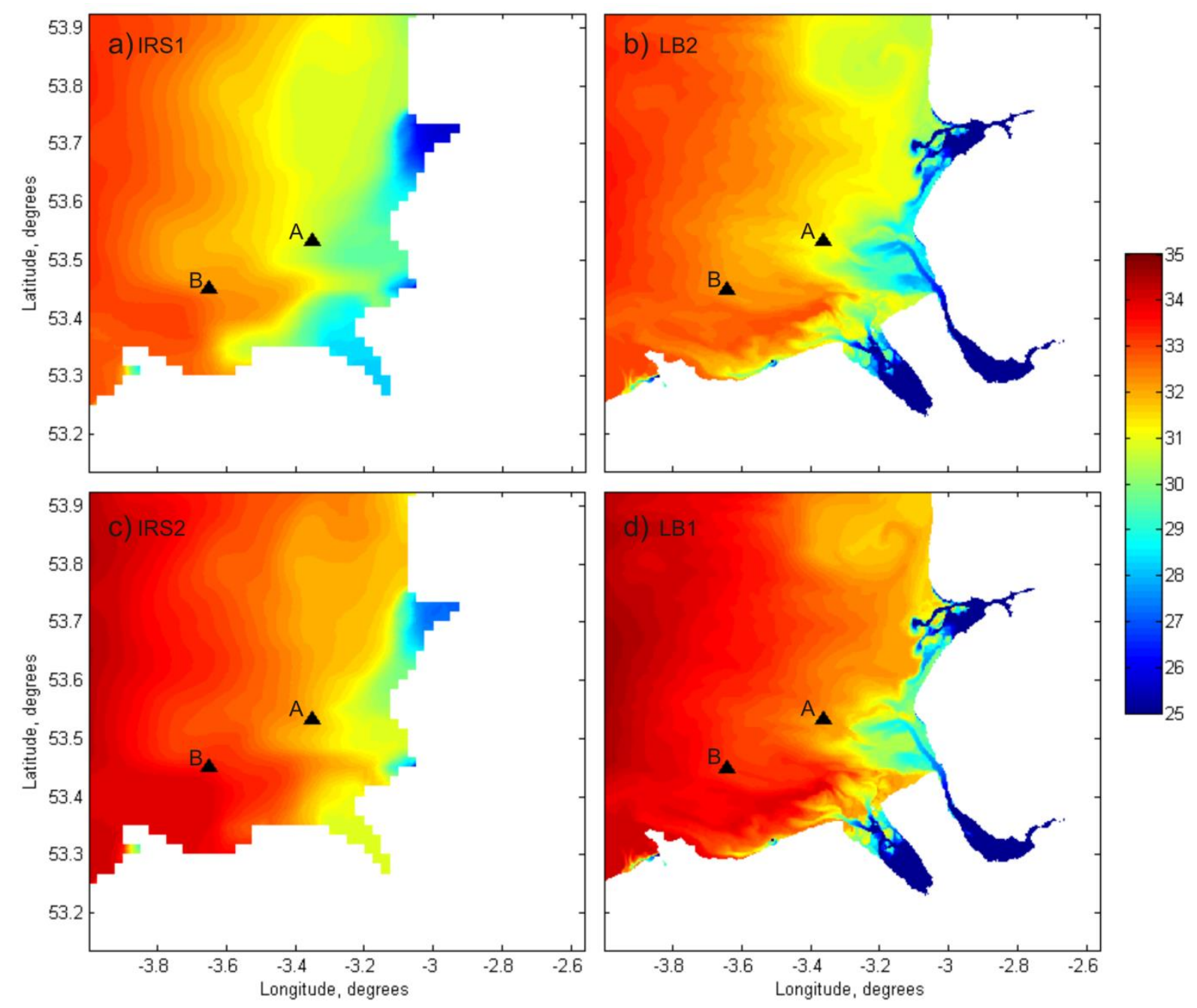

Fig. 8. The surface salinity (psu) when the ROFI reached its greatest offshore extent (day 81).

Results are shown for the unbiased a) IRS1, b) LB2 and biased c) IRS2 and d) LB1 model simulations as described in Tables 1 and 2. Site A (eastern most) and B (western most) are indicated by solid triangles to highlight the position and structure of the plume with respect to the fixed moorings (Figs. 5 - 7). 


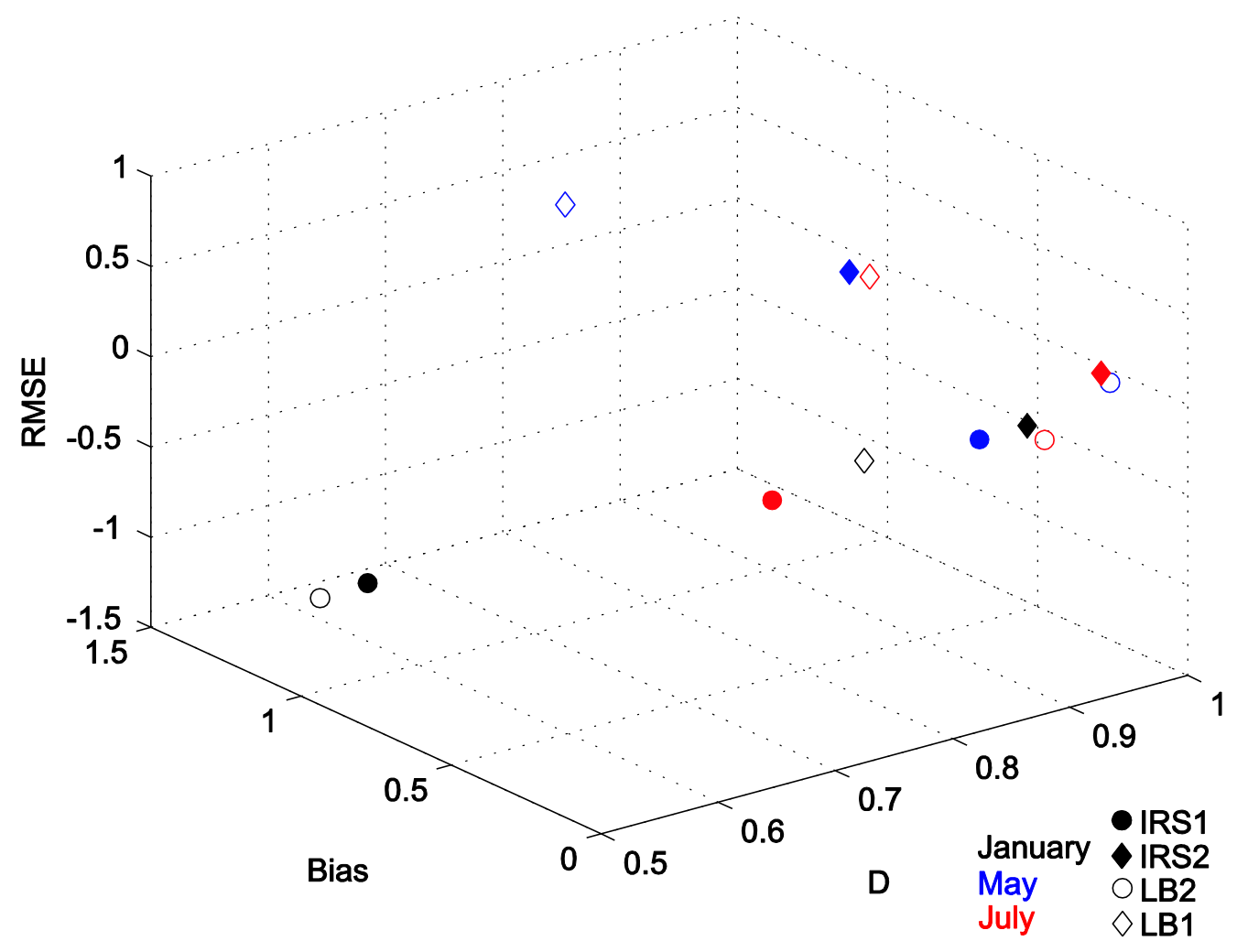

Fig. 9. Error metrics, Eqs. 1-3, assessing density anomaly during each cruise for the model simulations in Tables 1 and 2 . 


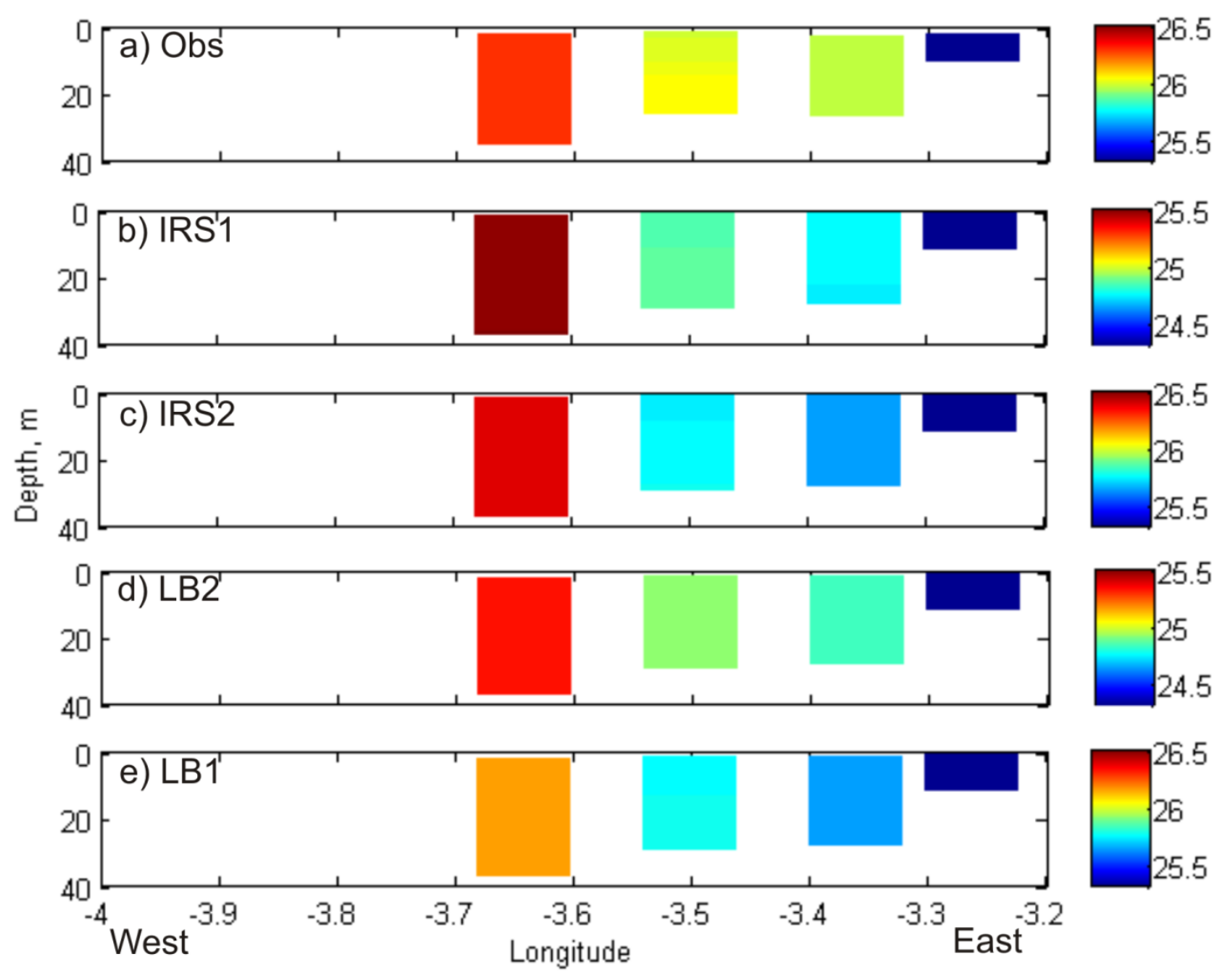

Fig. 10. The density anomaly in January for the CTD transect at $53.533^{\circ} \mathrm{N}$ crossing the plume from the Mersey. The observations (a) are presented alongside the model results for IRS1 (b), IRS2 (c), LB2 (d) and LB1 (e). Note the colour scale is modified for the IRS1 (b) and LB2 (d) to clearly show the modelled water structure of the transect for the unbiased simulations. 

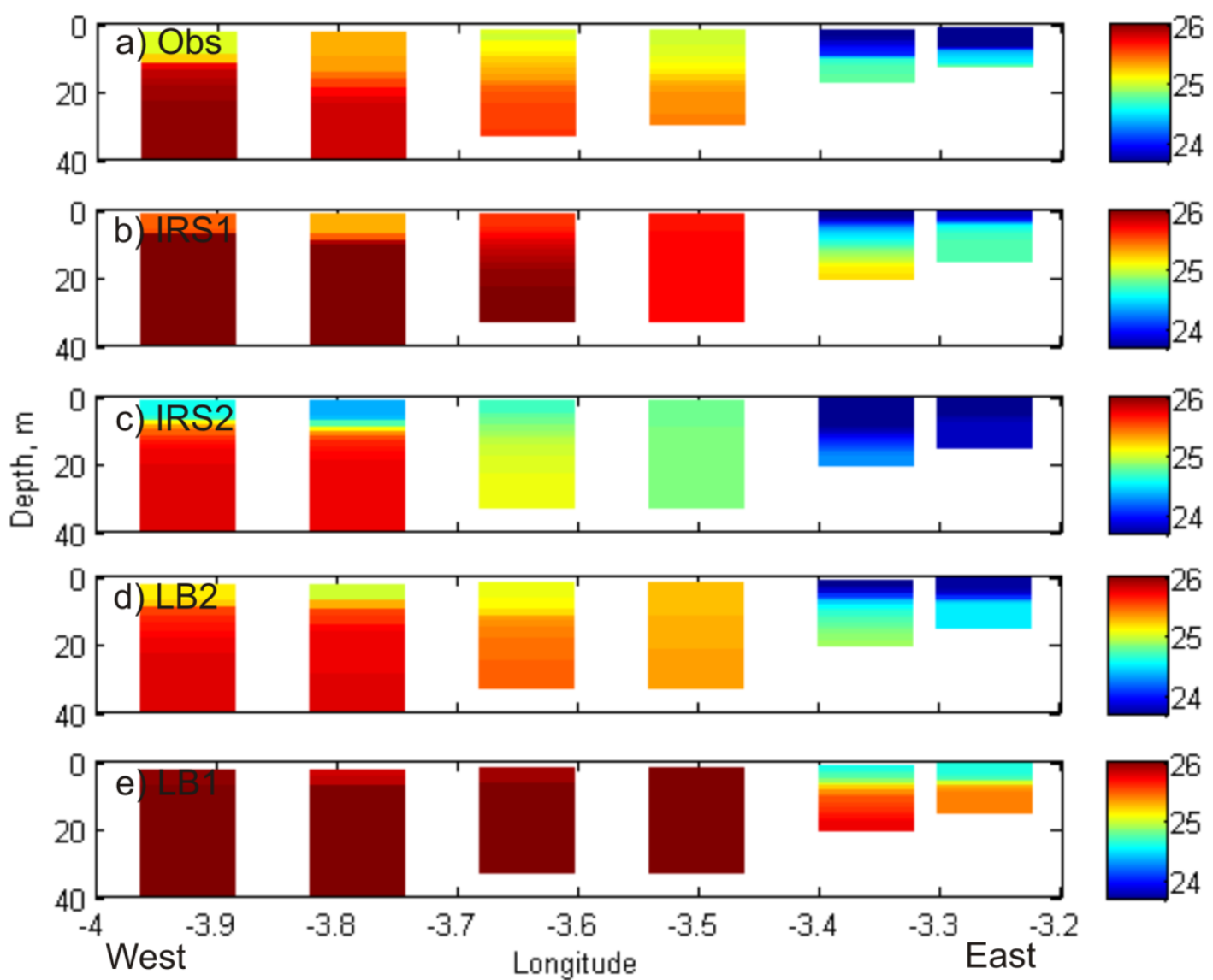

Fig. 11. As in Fig.7 but for the May cruise. A consistent colour scale is used in this case. 


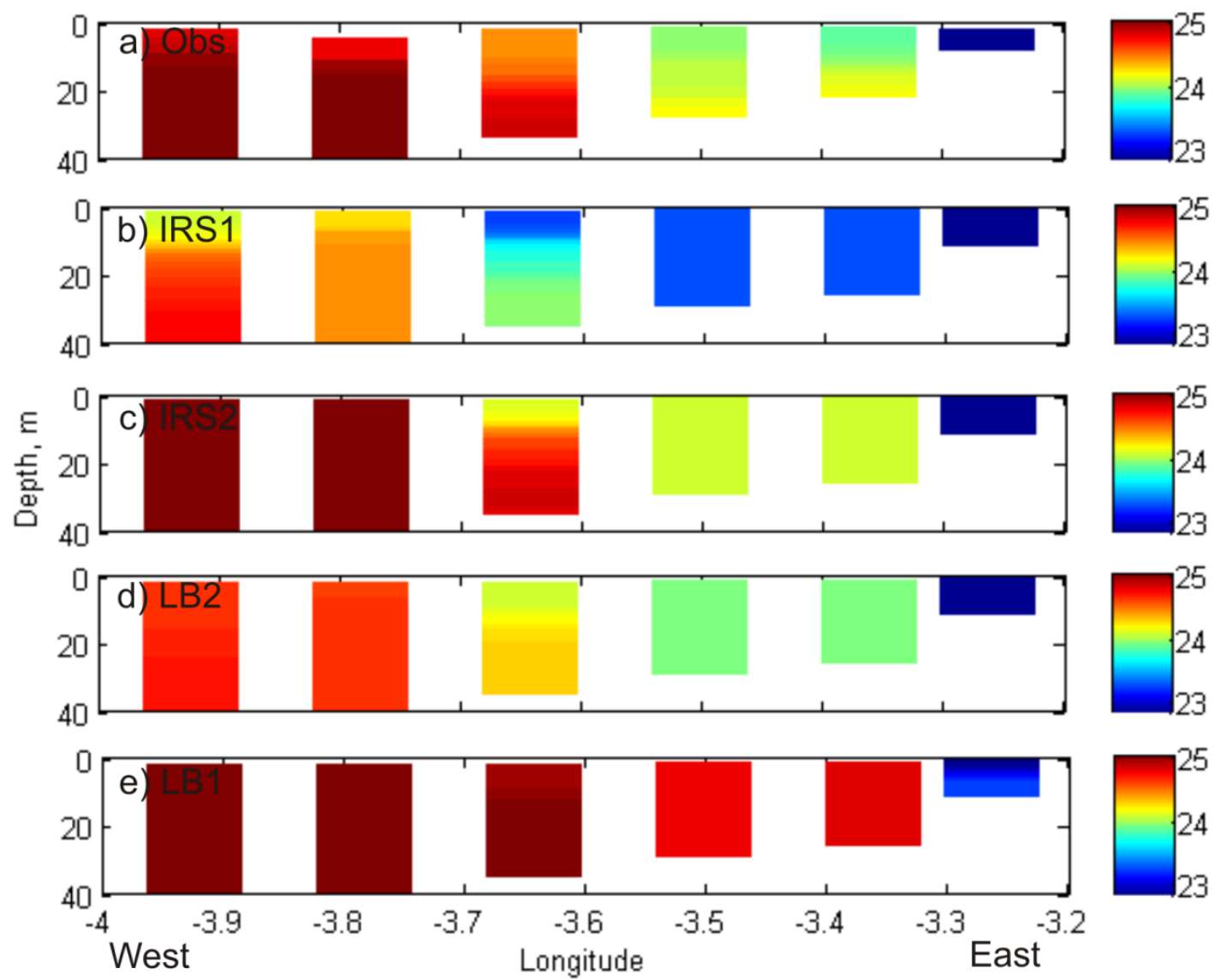

Fig. 12. As in Fig.7 but for the July cruise. A consistent colour scale is used in this case. 
Table 1: The Irish Sea (IRS) model simulations. IRS2 highlighted in bold is considered to be the optimum model setup for Liverpool Bay at this resolution.

$\begin{array}{lll}\text { Simulation identifier Initial conditions } & \text { Boundary conditions }\end{array}$

$\begin{array}{lll}\text { IRS1 AMM pre-operational } & \text { AMM pre-operational }\end{array}$

IRS2

AMM pre-operational + 1.15 psu bias

IRS pre-operational
AMM pre-operational

AMM pre-operational

Table 2: The Liverpool Bay (LB) model simulations. LB5 highlighted in bold is considered to be the optimum model setup for Liverpool Bay at this resolution.

$\begin{array}{lll}\text { Simulation identifier } \quad \text { Initial conditions } & \text { Boundary conditions }\end{array}$

\begin{tabular}{lll}
\hline LB1 & IRS pre-operational & IRS2 (Table 1) \\
LB2 & IRS pre-operational & IRS1 (Table 1) \\
LB3 & IRS pre-operational + 1. 15 psu bias & IRS1 (Table 1) \\
LB4 & IRS pre-operational + 1.89 psu bias & IRS1 (Table 1) \\
LB5 & IRS pre-operational & IRS3 (Table 1)
\end{tabular}

